\title{
Study of the cwaRS-IdcA Operon Coding a Two-Component System and a Putative I,d-Carboxypeptidase in Lactobacillus paracasei
}

\begin{abstract}
Hélène Scornec ${ }^{1}$, Aurore Palud ${ }^{1}$, Thierry Pédron 2,3 , Richard Wheeler 4,5 , Clément Petitgonnet ${ }^{1}$, Ivo Gomperts Boneca ${ }^{4,5}$, Jean-François Cavin ${ }^{1}$, Philippe J. Sansonetti ${ }^{2,3,6}$ and Hélène Licandro ${ }^{1 *}$
\end{abstract}

${ }^{1}$ PAM UMR, AgroSup Dijon, Université de Bourgogne Franche-Comté, Dijon, France, ${ }^{2}$ Unité de Pathogénie Microbienne Moléculaire, Institut Pasteur, Paris, France, ${ }^{3}$ Unité INSERM, Institut Pasteur, Paris, France, ${ }^{4}$ Unité de Biologie et Génétique de la Paroi Bactérienne, Institut Pasteur, Paris, France, ${ }^{5}$ Avenir Group, INSERM, Paris, France, ${ }^{6}$ Chaire de Microbiologie et Maladies Infectieuses, Collège de France, Paris, France

The cell surface is the primary recognition site between the bacterium and the host. An operon of three genes, LSEI_0219 (cwaR), LSEI_0220 (cwaS), and LSEI_0221 $(I d c A)$, has been previously identified as required for the establishment of Lactobacillus paracasei in the gut. The genes cwaR and cwaS encode a predicted two-component system (TCS) and IdcA a predicted D-alanyl-D-alanine carboxypeptidase which is a peptidoglycan (PG) biosynthesis enzyme. We explored the functionality and the physiological role of these three genes, particularly their impact on the bacterial cell wall architecture and on the bacterial adaptation to environmental perturbations in the gut. The functionality of CwaS/R proteins as a TCS has been demonstrated by biochemical analysis. It is involved in the transcriptional regulation of several genes of the PG biosynthesis. Analysis of the muropeptides of PG in mutants allowed us to re-annotate LSEI_0221 as a putative L,D-carboxypeptidase (LdcA). The absence of this protein coincided with a decrease of two surface antigens: LSEI_0020, corresponding to p40 or msp2 whose implication in the host epithelial homeostasis has been recently studied, and LSEI_2029 which has never been functionally characterized. The inactivation of each of these three genes induces susceptibility to antimicrobial peptides (hBD1, hBD2, and CCL20), which could be the main cause of the gut establishment deficiency. Thus, this operon is necessary for the presence of two surface antigens and for a suitable cell wall architecture.

Keywords: peptidoglycan, two-component system, gene regulation, carboxypeptidase, antimicrobial peptides, lactic acid bacteria, host-microbe interaction

\section{INTRODUCTION}

Advances in metagenomics have highlighted the diversity of functions encoded by the microbiota, the variability of the microbiota composition between individuals, and the link between gut microbiota composition and chronic diseases, cancer, and obesity (Arumugam et al., 2011; Lozupone et al., 2012; The Human Microbiome Project Consortium, 2012; Sonnenburg and Bäckhed, 2016; Zitvogel et al., 2017). The importance of intestinal microbiota for health is recognized, and scientific efforts are currently focused on 
understanding the ecological successions of microbes and microbial functions during host-microbe interactions (Gensollen et al., 2016; Milani et al., 2017; Sommer et al., 2017). Some bacterial molecules have been identified to act as signaling molecules during this interaction, such as short-chain fatty acids and CpG-DNA (cytosine-phosphate-guanine site in the single-stranded linear sequence) (Koh et al., 2016). The main components of this interaction, classed as microbe-associated molecular patterns (MAMPs), come from the bacterial cell envelope [peptidoglycan (PG), lipopolysaccharides, flagellin, teichoic acids]. They can act either in the cell wall-bound form or as released fragments for cell-to-cell signaling (Takeuchi and Akira, 2010; Clemente et al., 2012; Matos et al., 2017).

As natural inhabitants of fermented food and feed (plants, meat, dairy), as well as the oral cavity, gut, and genital tracts, Lactobacillus species share a good genetic arsenal to fit new and sometimes harsh environments (Makarova et al., 2006; Fiocco et al., 2019). Their high adaptability to environmental perturbations results from an accurate coordination of cellular processes (production of chaperones and DNA repair proteins, induction of metabolic pathways or transport systems, modifications of membrane composition) mediated by networks of regulators and also two-component systems (TCSs) (van de Guchte et al., 2002). Lactobacillus casei/paracasei is one of the best-equipped of the lactic acid bacteria $(\mathrm{LAB})$ to sense and respond to environmental changes since the genome of $L$. paracasei ATCC 334 possesses 16 complete and one incomplete TCSs and 124 transcriptional regulators (Cai et al., 2009; Alcantara et al., 2011) (and our in silico analysis). Their resistance can also be attributed to their cell wall architecture which is the base for the maintenance of cell shape and integrity and, via the proteins exposed, for direct interaction with the biotic or abiotic environment (ChapotChartier and Kulakauskas, 2014). The cell wall of Lactobacillus is composed of a PG layer decorated with teichoic acids and anchored proteins like PG hydrolases and LPxTG proteins that surround the cytoplasmic membrane.

To explore the way commensal bacteria begin to colonize the gut, we have taken L. paracasei ATCC 334 (formerly named L. casei ATCC 334) as a model foodborne bacterium able to establish, at least transiently, in the gut and interact with the host (Licandro-Seraut et al., 2014). L. paracasei is one of the most studied LAB species in food microbiology, particularly for its flavoring abilities (Di Renzo et al., 2018; Stefanovic et al., 2018) and for its probiotic properties (Arioli et al., 2018; Fehlbaum et al., 2019). Using signature-tagged mutagenesis coupled with screening in a ligated rabbit ileal-loop model, we have identified a core of 47 genes in L. paracasei essential for gut establishment, the first step of colonization. Indeed, five genes could be attributed to adaptation to environment (three regulators and one TCSpredicted) and six genes to biogenesis of the cell wall [three genes implicated in D-alanylation of lipoteichoic acids (LTAs), two transporters, and one D-alanyl-D-alanine carboxypeptidasepredicted]. Among them, three consecutive, identically oriented genes were identified: LSEI_0219, LSEI_0220, and LSEI_0221. The LSEI_0219-0220 genes caught our attention since they encode the only TCS identified in this screening. Also, LSEI_0221 is the only gene annotated as a putative D-alanyl-D-alanine (DAla-D-Ala) carboxypeptidase, penicillin-binding protein (PBP) in L. paracasei (Cai et al., 2009). Genetic location of LSEI_02190220 presumes a role of this TCS in the cell wall biogenesis. In light of the results reported hereafter, LSEI_0219, LSEI_0220, and LSEI_0221 genes were named $c w a R, c w a S$, and $l d c A$, respectively. In this study, we explored biochemical functions and physiological roles of $c w a R, c w a S$, and $l d c A$ genes and their corresponding proteins. We also assessed the consequences of their inactivation, which may explain the defect in surviving in the gut previously observed.

\section{MATERIALS AND METHODS}

\section{Bacterial Strains, Plasmids, and Growth Conditions}

Bacterial strains and plasmids used in this study are listed in Table 1. L. paracasei ATCC 334 and mutants were grown statically at $37^{\circ} \mathrm{C}$ in MRS medium (Difco), supplemented with $5 \mu \mathrm{g} \cdot \mathrm{ml}^{-1}$ erythromycin for mutants. The following mutants, McwaR, McwaS, MldcA, MdltA, MdltC, and dltD, were obtained by transposon mutagenesis with $\mathrm{P}_{\text {junc }}$-TpaseIS $\mathrm{T}_{1223}$ and identified by individual sequencing as previously described (LicandroSeraut et al., 2012, 2014; Scornec et al., 2014). Escherichia coli strains TG1 and BL21(DE3) were used as cloning and expression hosts, respectively. They were grown in LB medium at $37^{\circ} \mathrm{C}$ with shaking. Recombinant plasmids in E. coli were selected in LB medium containing $50 \mu \mathrm{g} \cdot \mathrm{ml}^{-1}$ kanamycin.

\section{DNA Techniques}

All DNA manipulations were performed according to standard procedures (Sambrook et al., 1989). Plasmids were isolated by using Nucleospin plasmid miniprep kit (BioBasics). PCR was performed using 0.02 unit of Phusion High-Fidelity DNA polymerase (Thermo Scientific).

\section{Stress Conditions for qRT-PCR Analysis}

For 15-min stresses, culture in exponential phase [OD at $600 \mathrm{~nm}$ $(\mathrm{OD})=0.6]$ was suspended in a volume of MRS supplemented with $\mathrm{NaCl} 1 \mathrm{M}$, bile $3 \mathrm{~g} / \mathrm{l}$, acid ( $\mathrm{HCl}) \mathrm{pH}$ 3.0, lactic acid $\mathrm{pH}$ 3.0 , penicillin $0.1 \mu \mathrm{g} / \mathrm{ml}$, vancomycin $0.5 \mathrm{~g} / \mathrm{l}$, or ethanol $15 \%$ (v/v) (Palud et al., 2018). For thermal stresses, phosphate buffer $\left(20 \mathrm{mM} \mathrm{pH} \mathrm{6.0)}\right.$ at 4 or $50^{\circ} \mathrm{C}$ was used instead of MRS. For sodium dodecyl sulfate (SDS) treatment, phosphate buffer was supplemented with SDS $0.05 \%(m / v)$. MRS or phosphate buffer was used as the reference.

\section{RNA Extractions and qRT-PCR Analysis}

PG-related genes were selected based on L. paracasei ATCC 334 genome annotation (NCBI annotation number NC_008526.1 and NC_008502.1).

Whole RNA was extracted from $50 \mathrm{ml}$ of culture in exponential phase $(\mathrm{OD}=0.6)$ and $10 \mathrm{ml}$ in stationary phase $(\mathrm{OD}=3.5)$ after bead beating disruption using Tri reagent method (Sigma), and cDNA were synthesized as previously 
TABLE 1 | Bacterial strains and plasmids.

\begin{tabular}{|c|c|c|}
\hline Strains and plasmids & Genotype and/or relevant feature(s) & Source or reference \\
\hline \multicolumn{3}{|l|}{ Strains } \\
\hline L. paracasei ATCC 334 & Wild type, CIP 107868, genome sequenced & Collection Institut Pasteur, France \\
\hline McwaR mutant & ATCC 334 LSEI_0219:pVI110, Erm & Licandro-Seraut et al., 2014 \\
\hline McwaS mutant & ATCC 334 LSEI_0220:pVI110, Erm ${ }^{R}$ & Licandro-Seraut et al., 2014 \\
\hline $\mathrm{M} / d c A$ mutant & ATCC 334 LSEI_0221:pVI110, Erm ${ }^{R}$ & Licandro-Seraut et al., 2014 \\
\hline MdltA mutant & ATCC 334 LSEI_0794:pVI110, Erm ${ }^{R}$ & Licandro-Seraut et al., 2014 \\
\hline MdltC mutant & ATCC 334 LSEI_0796:pVI110, Erm ${ }^{R}$ & Licandro-Seraut et al., 2014 \\
\hline MdltD mutant & ATCC 334 LSEl_0797:pVI110, Erm ${ }^{R}$ & Licandro-Seraut et al., 2014 \\
\hline E. coli TG1 & SupE hsd $\Delta 5$ thi $\Delta\left(\right.$ lac-proAB)F' [tra D36 pro $A B^{+}$lac 19 lac $\left.Z \Delta M 15\right]$ & Gibson, 1984 \\
\hline E. coli BL21 (DE3) & $\mathrm{F}^{-}$ompT hsdS ${ }_{B}\left(\mathrm{rB}^{-} \mathrm{mB}^{-}\right) \mathrm{gal} d \mathrm{~cm}(\mathrm{DE} 3)$ & Invitrogen \\
\hline E. coli TG1 pETcwaR & $\begin{array}{l}\left.\text { SupE hsd } \Delta 5 \text { thi } \Delta \text { (lac-proAB)F' [tra D36 pro } A B^{+} \text {lac } 19 \text { lacZ } \Delta M 15\right] \\
\text { with pETcwaR }\end{array}$ & This work \\
\hline E.coli TG1 pETccwaS & $\begin{array}{l}\left.\text { SupE hsd } \Delta 5 \text { thi } \Delta \text { (lac-proAB)F' [tra D36 pro } A B^{+} \text {lac } 19 \text { lacZ } \Delta M 15\right] \\
\text { with pETccwaS }\end{array}$ & This work \\
\hline \multicolumn{3}{|l|}{ Plasmids } \\
\hline pET28a+ & $\begin{array}{l}\mathrm{Kan}^{\mathrm{R}} \text {, vector for overexpression of His-tagged proteins using the } \mathrm{T7} \\
\text { bacteriophage promoter }\end{array}$ & Novagen \\
\hline pETcwaR & $\begin{array}{l}\text { pET28a + containing LSEl_0219 gene between Ncol and Xhol sites } \\
\text { to overproduce CwaR His } 6 \text { tag }\end{array}$ & This work \\
\hline pETccwaS & $\begin{array}{l}\text { pET28a + containing truncated LSEI_0220 gene coding for } \\
\text { residues } 137-396 \text { of the HK protein between Ncol and Xhol sites to } \\
\text { overproduce cCwaS His } 6 \text { tag }\end{array}$ & This work \\
\hline
\end{tabular}

described (Licandro-Seraut et al., 2008). Quantitative reverse transcriptase PCRs (qRT-PCR) were performed in a CFX384 real-time detection system (Bio-Rad). The total volume of the PCR mixture was $15 \mu$ l containing $1 \mathrm{X}$ SsoAdvanced ${ }^{\mathrm{TM}}$ Universal SYBR $^{\circledR}$ Green Supermix (Bio-Rad), 25 ng cDNA, and $0.8 \mu \mathrm{M}$ of each primer (Supplementary Table S1). PCR amplification was one step at $95^{\circ} \mathrm{C}$ for $30 \mathrm{~s}$ followed by 40 cycles of $95^{\circ} \mathrm{C}$ for $5 \mathrm{~s}$ and $60^{\circ} \mathrm{C}$ for $10 \mathrm{~s}$. An additional cooling step from $90^{\circ} \mathrm{C}$ to $60^{\circ} \mathrm{C}\left(3^{\circ} \mathrm{C} / \mathrm{min}\right)$ was performed to establish a melting curve in order to verify the homogeneity of the amplicon. All sample and primer combinations were assessed in three biological replicates with at least two technical replicates per biological replicate. In each run, a negative control using sterile water instead of cDNA was included. Normalized expression levels were calculated using the comparative critical threshold $(\Delta \Delta \mathrm{Cq})$ method (Hellemans et al., 2007). The data were processed with CFX Manager Software (Bio-Rad).

\section{Plasmid Constructs and Generation of E. coli Strains Overproducing RR0219 and cHK0220}

Full-length cwas was amplified using primers LSEI_0219FbisNcoI (5'-ATACCATGGGCAAAATTTTAATTG TTGA-3') and LSEI_0219RXhoI (5'-GTGCTCGAGGGCCT CAACCTTATAGCCGA-3'), and the cytosolic domain of CwaS, cCwaS (residues 137 to 396) was amplified using primers LSEI_0220FHAMPNcoI (5'-ATACCATGGGCACCG TCAATTCAATGGCC-3') and LSEI_0220RXhoI (5'-GTG CTCGAGTTTTGACTTTCCTGCTTCCT-3') from the L. paracasei genomic DNA. The forward primers contained the NcoI site in frame with the translation start codon, and the reverse primers contained the XhoI site. After restriction digestion, the amplicons were ligated to NcoI-XhoI digested pET28a+ expression vector using T4 DNA ligase HC (Fermentas). The resulting ligation products were directly transformed by electroporation into the E. coli TG1 strain as described by Dower et al. (1988) to obtain pETCwaR and pETcCwaS constructs. Plasmids were isolated from selected transformants and subjected to sequencing reactions (GATC Biotech). The pETCwaR and the pETcCwaS were transformed into competent $E$. coli BL21 (DE3) cells by the $\mathrm{CaCl}_{2}$ procedure (Cohen et al., 1972), and protein expression was induced at $\mathrm{OD} \approx$ $0.5 \mathrm{in} 1 \mathrm{~L}$ of $\mathrm{LB}$ with the addition of $0.5 \mathrm{mM}$ IPTG for $3 \mathrm{~h}$ at $37^{\circ} \mathrm{C}$.

\section{Cell Extracts and Protein Purification}

Escherichia coli or Lactobacillus paracasei cell extracts were prepared as previously described (Gury et al., 2009). For protein purification, the filtrates were applied to a Protino ${ }^{\circledR}$ Ni-NTA column (Macherey-Nagel), and the CwaR and cCwaS proteins were eluted with imidazole gradient.

\section{Autophosphorylation and Phosphotransfer Assay}

Immediately before use, $0.5 \mathrm{ml}$ of purified $\mathrm{CwaR}$ and $\mathrm{cCwaS}$ proteins were concentrated using an ultrafree 0.5 centrifugal filter unit (Millipore). The autophosphorylation procedure was adapted from Abo-Amer et al. (2004). Briefly, $6 \mu \mathrm{g}$ of cCwaS protein was incubated in a final volume of $20 \mu \mathrm{l}$ phosphorylation buffer containing $50 \mathrm{mM}$ Tris- $\mathrm{HCl} \mathrm{pH} \mathrm{7.5,} 2.5 \mathrm{mM} \mathrm{MnCl}_{2}, 5 \mathrm{mM}$ $\mathrm{MgCl}_{2}, 50 \mathrm{mM} \mathrm{KCl}, 20 \mu \mathrm{Ci}$ of $\left[\gamma^{-}{ }^{32} \mathrm{P}\right]$-ATP $(3,000 \mathrm{Ci} / \mathrm{mmol})$. Reaction was stopped by addition of $4 \mu \mathrm{l}$ SDS loading buffer. For the phosphotransfer reaction, $10 \mu \mathrm{g}$ of CwaR protein was added 
after $60 \mathrm{~min}$ of cCwaS protein autophosphorylation, and samples were quenched by the addition of $5 \mu \mathrm{l}$ SDS loading buffer. The reaction mixtures were analyzed by $12.5 \%$ SDS-polyacrylamide gel electrophoresis (SDS-PAGE), followed by autoradiography.

\section{Phosphorylation of CwaR Protein by Small-Molecule Phosphoryl Donors}

The phosphorylation by acetyl phosphate protocol was adapted from Molle and Buttner (2000) and Hutchings et al. (2006). $\left[{ }^{32} \mathrm{P}\right]$-acetyl phosphate was prepared by incubating acetate kinase (0.4 units; A7437, Sigma) in $55 \mu \mathrm{l}$ of $25 \mathrm{mM}$ Tris- $\mathrm{HCl} \mathrm{pH} \mathrm{7.5,}$ $60 \mathrm{mM}$ potassium acetate, $10 \mathrm{mM} \mathrm{MgCl}_{2}, 100 \mu \mathrm{Ci}\left[\gamma^{32} \mathrm{P}\right]$-ATP $(3,000 \mathrm{Ci} / \mathrm{mmol})$ for $30 \mathrm{~min}$ at $25^{\circ} \mathrm{C}$. The $\left[{ }^{32} \mathrm{P}\right]$-acetyl phosphate

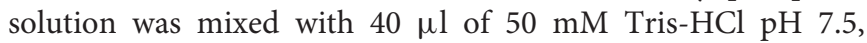
$2.5 \mathrm{mM} \mathrm{MnCl}_{2}, 5 \mathrm{mM} \mathrm{MgCl}_{2}$, and $50 \mathrm{mM} \mathrm{KCl}$ containing $40 \mu \mathrm{g}$ of CwaR protein. After incubation at $37^{\circ} \mathrm{C}$, samples of $18 \mu \mathrm{l}$ were quenched by addition of $2 \mu \mathrm{l}$ of SDS loading buffer and analyzed by a $12.5 \%$ SDS-PAGE, followed by autoradiography. RR0219 protein $(3 \mu \mathrm{g})$ was incubated with $60 \mathrm{mM}$ of acetyl phosphate $50 \mathrm{mM}$ Tris- $\mathrm{HCl} \mathrm{pH} 7.5,2.5 \mathrm{mM} \mathrm{MnCl}_{2}, 5 \mathrm{mM}$ $\mathrm{MgCl}_{2}$, and $50 \mathrm{mM} \mathrm{KCl}$.

\section{Electrophoretic Mobility Shift Assays}

Electrophoretic mobility shift assays (EMSAs) were carried out on cytosolic protein extract as previously described with some modifications (Gury et al., 2004). The 443-pb DNA probe, named PromcwaR, corresponding to the whole LSEI_0218-LSEI_0219 intergenic region was PCR amplified with primers P0219F-189 (5'-GCTAAGGCTTTTGTCAATATGG-3') and P0219R254 (5'CTTAGTAATTCGACGATTTC-3'). The fragment was $3^{\prime}$ endlabeled with digoxigenin (DIG)-11-ddUTP with dig gel shift kit, second generation (Roche) according to the manufacturer's recommendation. Before binding reactions, protein extract was heated for $10 \mathrm{~min}$ at $65^{\circ} \mathrm{C}$, then it was incubated with $1 \mu \mathrm{l}$ of $1 / 500$ PromcwaR probe in $15 \mathrm{mM}$ Tris- $\mathrm{HCl}$ $\mathrm{pH} 7.5,5 \%$ glycerol (v/v), $2 \mathrm{mM}$ EDTA, $50 \mathrm{mM} \mathrm{NaCl}$, $25 \mathrm{mM} \mathrm{KCl}, 2.5 \mathrm{mM} \mathrm{MgCl}, 2 \mathrm{mM} \mathrm{DTT}, 2.5 \mu \mathrm{g} \cdot \mathrm{ml}^{-1}$ of bovine serum albumin (BSA) and $2.5 \mu \mathrm{g} \cdot \mathrm{ml}^{-1}$ of salmon sperm DNA as an unspecific DNA competitor in a $15-\mu 1$ reaction volume for $20 \mathrm{~min}$ at $30^{\circ} \mathrm{C}$. The samples were resolved onto 5\% (w/v) PAGE gel in $20 \mathrm{mM}$ Tris- $\mathrm{HCl}, \mathrm{pH}$ 7.8, $400 \mathrm{mM}$ glycine, and $1 \mathrm{mM}$ EDTA at $4^{\circ} \mathrm{C}$. The DNA was transferred to a nylon membrane by electroblotting, probed with anti-DIG-AP antibody (Roche), and visualized using chemiluminescence.

\section{Transmission Electron Microscopy}

Cells were pelleted by centrifugation and fixed overnight at $4^{\circ} \mathrm{C}$ in $3 \%$ glutaraldehyde (v/v), $2 \%$ formaldehyde (v/v), $5 \mathrm{mM}$ $\mathrm{MgCl}_{2}$, and $0.1 \mathrm{M}$ phosphate buffer, $\mathrm{pH}$ 7.2. Then, cells were pelleted and embedded in $2.25 \%(\mathrm{w} / \mathrm{v})$ low-gelling temperature agarose. Samples were fixed in $0.5 \% \mathrm{OsO}_{4}(\mathrm{~m} / \mathrm{v})$ in $0.1 \mathrm{M}$ phosphate buffer $\mathrm{pH} 7.2$ for $1 \mathrm{~h}$ at $4^{\circ} \mathrm{C}$, then dehydrated through graded concentrations of ethanol then propylene oxide, and embedded in Epon 812 (Merck, Lyon, France). Ultrathin sections were stained with PATag method as described previously
(Thiéry, 1967) and observed at $80 \mathrm{kV}$ on a transmission electron microscope (H-7500, Hitachi, Tokyo).

\section{Peptidoglycan Extraction and Analysis}

Lactobacillus paracasei ATCC 334 and the MldcA mutant were purified and analyzed as described by de Jonge et al. (1992) with some modifications (Girardin et al., 2003). The traces are representative data of the three replicates.

\section{Minimal Inhibitory Concentration Determination}

The minimal inhibitory concentrations (MICs) of penicillin, bacitracin, nisin, and vancomycin against L. paracasei ATCC 334 and $\mathrm{MldcA}$ mutant were determined by a microdilution technique. Overnight cell cultures were diluted 1:100 in fresh MRS media and added in individual wells containing various concentrations of antibiotic (series of twofold dilutions). The MIC was defined as the lowest antimicrobial concentration preventing visible turbidity after $24 \mathrm{~h}$ of incubation at $37^{\circ} \mathrm{C}$.

\section{Microbial Adhesion to Solvents Test}

A Microbial Adhesion To Solvents (MATS) test was performed as described previously (Bellon-Fontaine et al., 1996) with chloroform (acidic solvent and electron acceptor), ethyl acetate (basic solvent and electron donor), and hexadecane (hydrophobic solvent). Overnight cultures of each strain were washed and suspended at $\mathrm{OD}=0.4$ in phosphate-buffered saline (PBS, $\mathrm{pH}$ 7.4) $\left(\mathrm{A}_{0}\right)$. This suspension $(3 \mathrm{ml})$ was mixed with $1 \mathrm{ml}$ of solvent (chloroform, ethyl acetate, or hexadecane) for $3 \mathrm{~min}$ with vortex. After $15 \mathrm{~min}$ (partition of phases), the OD of the aqueous phase was measured $\left(A_{1}\right)$. The percentage of adhesion was calculated as follows: $\%$ adhesion $=100 \times\left(\left(\mathrm{A}_{0}-\mathrm{A}_{1}\right) / \mathrm{A}_{0}\right)$. All experiments were repeated at least three times on three biological repeats.

\section{Triton X-100-Induced Autolysis}

Lactobacillus paracasei strains were grown on MRS medium to mid-exponential phase $(\mathrm{OD}=0.8)$. Cells were harvested by centrifugation, washed, and then suspended to OD of 1.0 in a $50 \mathrm{mM}$ potassium phosphate buffer, $\mathrm{pH}$ 7.0, supplemented with $0.05 \%$ Triton X-100 (v/v). Cell suspensions were then transferred in 96-well sterile clear microplates (Nunc) and incubated $24 \mathrm{~h}$ at $30^{\circ} \mathrm{C}$ under agitation. Autolysis was monitored by measuring the OD. All experiments were repeated at least three times on three biological repeats.

\section{Surface Protein Extraction and Identification}

Surface proteins were extracted by $5 \mathrm{M}$ of $\mathrm{LiCl}$ according to the Smit et al. (2001) procedure (Zhang et al., 2010). Briefly, $20 \mathrm{ml}$ of bacterial cultures were washed twice with ice distilled water. The cell pellets were suspended in $2 \mathrm{ml}$ of $5 \mathrm{M}$ of $\mathrm{LiCl}$ and incubated $1 \mathrm{~h}$ at $37^{\circ} \mathrm{C}$ with shaking. Suspensions were centrifuged $10,000 \mathrm{~g}$ at $10^{\circ} \mathrm{C}$ for $20 \mathrm{~min}$, then supernatants were precipitated with $4 \mathrm{ml}$ of cold acetone and incubated for $2 \mathrm{~h}$ at $-20^{\circ} \mathrm{C}$. The precipitated proteins were harvested by centrifugation $(10,000 \mathrm{~g}, 10 \mathrm{~min}$ at $\left.4^{\circ} \mathrm{C}\right)$. The precipitates were suspended in loading SDS buffer 
then boiled $3 \mathrm{~min}$ and analyzed by $12.5 \%$ SDS-PAGE. Briefly, for protein identifications, proteins were reduced, alkylated, then digested by trypsin (Promega) for $3 \mathrm{~h}$ at $37^{\circ} \mathrm{C}$. Tryptic digests were separated and analyzed by liquid chromatography coupled to tandem mass spectroscopy (LC-MS/MS) (nanoLC-ESI-Trap, Orbitrap ELITE, Thermo Scientific). Protein identification was performed using Proteome Discoverer 1.4 software against a protein database of L. paracasei ATCC 334 strain (GenBank: NC_008526.1 and NC_008502.1).

\section{Challenge in Stressful Conditions}

Overnight cultures were combined to get a proportion of $2 \%$ of mutant and $98 \%$ of ATCC 334. The resulting mixed cultures were washed with $\mathrm{PBS} \mathrm{pH} 7.4$, suspended to a final OD of 0.1 and challenged during $16 \mathrm{~h}$ at $37^{\circ} \mathrm{C}$ in diluted MRS $(1 / 20)$, used as a low-nutrient medium, and modified to obtain different stressful conditions: (i) low-nutrient, acidic $(\mathrm{HCl})(\mathrm{pH}$ 3.5), (ii) low-nutrient, bile supplemented (3 g. $\left.1^{-1}\right)$, (iii) lownutrient, lysozyme-supplemented $\left(10 \mathrm{~g} . \mathrm{l}^{-1}\right)$. The concentrations of mutant relative to ATCC 334 were determined by counting $\left(\mathrm{CFU} \cdot \mathrm{ml}^{-1}\right.$ ) on MRS + Ery $5 \mu \mathrm{g} \cdot \mathrm{ml}^{-1}$ and MRS plates. Mutant resistance to stress was assessed by determining the ratio of mutant to the ATCC 334 strain and comparing it to the initial ratio. The ratio with the control treatment (MRS diluted $1 / 20$ ) is the same before and after $16 \mathrm{~h}$ at $37^{\circ} \mathrm{C}$.

\section{Susceptibility to Cationic Peptides}

Cationic peptide susceptibility tests were performed as previously described (Hugo et al., 2012). Bacterial cultures (50 $\mu$ l) diluted in $50 \mathrm{mM} N$-2-hydroxyethylpoperazine-N9-2-ethanesulfonic acid (Hepes) buffer $\mathrm{pH} 7.5$ at $4.10^{7} \mathrm{CFU} \cdot \mathrm{ml}^{-1}$ were incubated with $50 \mu \mathrm{l}$ of hBD1, hBD2, LL37, or CCL20 (Abcam) at $20 \mu \mathrm{g} \cdot \mathrm{ml}^{-1}$ in Hepes buffer for $1 \mathrm{~h}$ at $37^{\circ} \mathrm{C}$ with $5 \% \mathrm{CO}_{2}$. Treated and non-treated bacteria were then incubated for $5 \mathrm{~min}$ at room temperature with $400 \mu \mathrm{l}$ of propidium iodide (PI) at $5 \mu \mathrm{g} \cdot \mathrm{ml}^{-1}$. The ratio of $\mathrm{PI}(+)$ cells was assessed by flow cytometry (FACSCanto, Diva software; Becton Dickinson, Mountain View, CA, United States). For each sample, 10,000 events were analyzed.

\section{Statistical Analyses and Software}

Data are expressed as arithmetic means \pm SD. The statistical analyses and the software used are indicated in the figure legends. Significant differences are indicated by $\left(^{*}\right)$ in the figures.

\section{RESULTS}

\section{Predictive Analysis of Operon cwaRS-IdcA and Polar Effect of the Transposon Insertion}

The cwaRS-ldcA predicted operon is composed of three genes (Figure 1A). The cwaR gene (LSEI_0219) belongs to the OmpR family and is a predicted response regulator (RR); the cwaS gene (LSEI_0220) is a predicted signal transduction histidine kinase (HK); the ldcA gene (LSEI_0221) is a predicted D-Ala-DAla carboxypeptidase (penicillin-binding protein). This family of
TCS is widely encountered in the bacterial world. In lactobacilli, it can be found in three different genetic organizations (Figure 1B). The TCS genes can be followed by a D-Ala-DAla carboxypeptidase as in L. paracasei or by another putative operon composed of murE (UDP-N-acteylmuramoylalanylD-glutamate-2,6-diaminopimelate ligase) and $\mathrm{racD}$ (aspartate racemase). In a few species, the locus is only composed of the TCS predicted operon. The first and the third configurations are observed in vancomycin-resistant Lactobacillus species (Mackey et al., 1993; Wilks et al., 2004; Klare et al., 2007; Balandino et al., 2008) except for L. fermentum which displays a variable strain-dependent vancomycin resistance (Rossetti et al., 2009). The second configuration is only observed in the vancomycinsusceptible species.

The coding sequences of $c w a R$ and $c w a S$ are separated by only five nucleotides, and $c w a S$ and $l d c A$ partially overlap. Thus, we assumed that these three genes were co-transcribed, which was confirmed by RT-PCR (data not shown). To determine if transposon insertion in the operon triggers a polar effect, qRT-PCR was performed for the three genes in the three corresponding mutants during exponential and stationary phases of growth (Figure 1C). Transcripts corresponding to $c w a S$ and $l d c A$ in $c w a R$ mutant (McwaR, pVI110 insertion in $c w a R$ gene) and transcripts corresponding to $l d c A$ in cwaS mutant (McwaS, pVI110 insertion in cwaS gene) were at least fivefold lower than in the ATCC 334 parental strain, meaning that transcription is affected downstream of the transposon insertion site. Also, transcript levels corresponding to genes upstream of the transposon insertion in these two mutants ( $\mathrm{McwaS}$ and $\mathrm{M} l d c A$ ) were similar to the ATCC 334, meaning that transposon insertion does not affect the stability of the upstream transcripts. In $\mathrm{M} l d c A$ mutant, the transcript for the $l d c A$ gene is not affected by insertional inactivation because the transposon insertion site is rather at the end of the $l d c A$ gene, but this locus corresponds to the middle of the predicted PBP5-C domain (Figure 1D) (Letunic et al., 2014). Thus, the protein function must be inactivated in this mutant. One possible assumption was that the defect of these three mutants in gut establishment could result from the inactivation of activity or the transcriptional decrease of $l d c A$ only.

\section{Physiological Role of D-Ala-D-Ala Carboxypeptidase for $L$. paracasei}

The $l d c A$ gene encodes a predicted D-Ala-D-Ala carboxypeptidase, a hydrolase involved in PG maturation which cleaves the pentapeptide side chain of PG strand between the fourth and the fifth (and last) alanine residues, thereby allowing transpeptidation of two PG strands. For L. casei/paracasei, the last $\mathrm{D}$-alanine residue is substituted by a D-lactate, conferring vancomycin resistance (Handwerger et al., 1994; Billot-Klein et al., 1997). This function is essential for PG synthesis and, since no other L. paracasei genes are predicted to encode this enzyme, $l d c A$ inactivation should be lethal. However, the $\mathrm{M} l d c A$ mutant is viable and grows as well as the ATCC 334 in culture medium (Licandro-Seraut et al., 2014). In view of this, it is likely that the annotation is not 
A

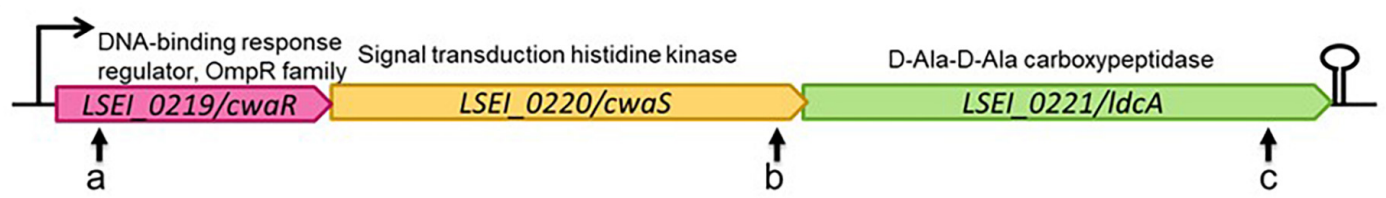

B

\begin{tabular}{|c|c|c|c|c|}
\hline$r r$ & $h k$ & dacA & & $\begin{array}{l}\text { L. casei, paracasei, buchneri, brevis, } \\
\text { fermentum, plantarum, rhamnosus, ruminis }\end{array}$ \\
\hline$r r$ & $h k$ & murE & racD & $\begin{array}{l}\text { L. amylovorus, amylolyticus, acidophilus, } \\
\text { crispatus, delbrueckii, gasseri, helveticus, } \\
\text { iners, jensenii, johnsonii }\end{array}$ \\
\hline$r r$ & $h k$ & & & L. reuteri, salivarius, vaginalis \\
\hline
\end{tabular}

c

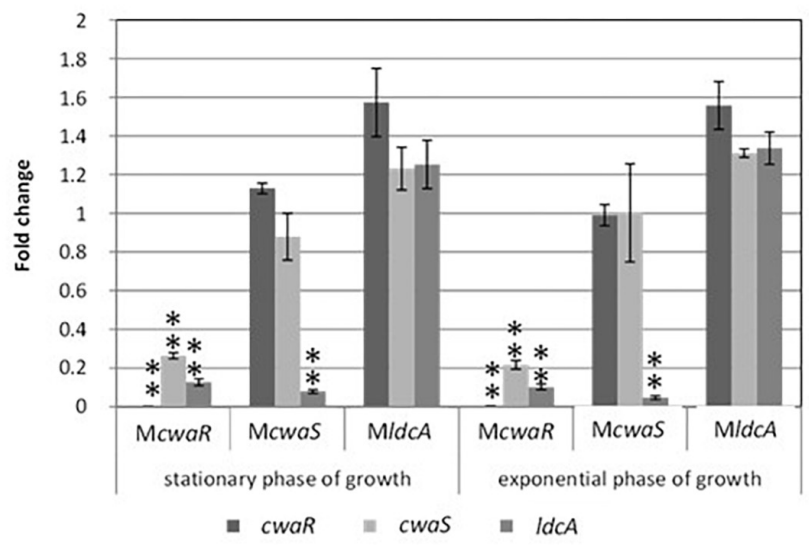

D

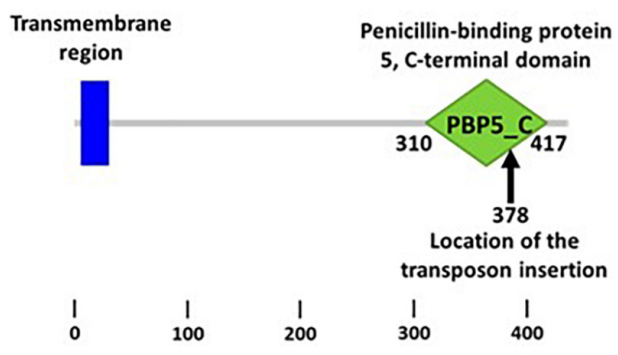

FIGURE 1 | Description of cwaRS-IdcA locus. (A) Locations of the different transposon insertions are shown with arrows a, b, and c for mutants McwaR, McwaS, and M/dcA, respectively. (B) Comparison of the organization in different Lactobacillus species. $r$, response regulator gene; $h k$, histidine kinase gene. (C) Relative transcript levels of $L$. casei mutants in stationary and exponential phase of growth in MRS broth. Transcript levels of each gene are expressed as the relative fold change, with L. paracasei ATCC 334 as the reference condition (fold change $=1$ ). Three biological repeats were performed, and bars indicate standard deviations. Statistical analysis was performed using the unpaired Student $t$-test: ${ }^{*} P<0.01 ;{ }^{* *} P<0.001$. (D) Smart schema of the domains within LdcA protein and location of the transposon in mutant M/dcA.

correct: the enzyme probably has another activity and there is another enzyme with the activity D-Ala-D-Ala carboxypeptidase like LSEI_0141 (annotated as a microcin self-immunity protein in ATCC 334 strain and as containing a peptidase domain with $\mathrm{D}, \mathrm{L}$ carboxypeptidase activity in other $L$. casei genomes) and LSEI_2553 (uncharacterized but annotated as containing a peptidase domain which has a possible carboxypeptidase activity). Thus, we decided to test whether $l d c A$ truly encoded the predicted function. Transmission electron microscopy (TEM) analysis of the MldcA mutant cultivated in exponential and early stationary phases of growth demonstrated that its cell morphology was similar to that of the ATCC 334 with length between 1 and $2 \mu \mathrm{m}$ and width between 0.4 and $0.6 \mu \mathrm{m}$ (Figure 2). Moreover, its PG thickness was not altered in the mutant with a value of $19.4 \pm 3.6 \mathrm{~nm}$.

To assign a biochemical function to the enzyme encoded by $l d c A$ gene, an analysis of muropeptides was performed on $\mathrm{M} l d c A$ mutant and ATCC 334 strains. The reversed phase highperformance liquid chromatography (RP-HPLC) muropeptide profiles revealed that the PG composition of $\mathrm{M} l d c A$ mutant differs from that of ATCC 334: tripeptides (peaks 1, 12, 36, $38,46,72,91)$ are less represented while tetrapeptides (peaks $6,10,18,51,78,95)$ are more represented. However, the PG cross-linking index was approximately the same (Figures 3A,B). These results suggest an L,D-carboxypeptidase activity, which cleaves the peptide chain of PG between L-Lys and DAla, rather than the predicted D,D-carboxypeptidase activity (Figure 3C). Thus, the LSEI_0221 gene was named $l d c A$ for its putative L,D-carboxypeptidase activity. The McwaR and McwaS mutants presented the same profiles as the MldcA mutant (data not shown).

\section{Consequences of the Peptidoglycan Composition on the Surface Properties}

The PG composition differences between MldcA mutant and ATCC 334 could impact surface properties that are essential for antibiotics and autolysis resistances and for biofilm formation 


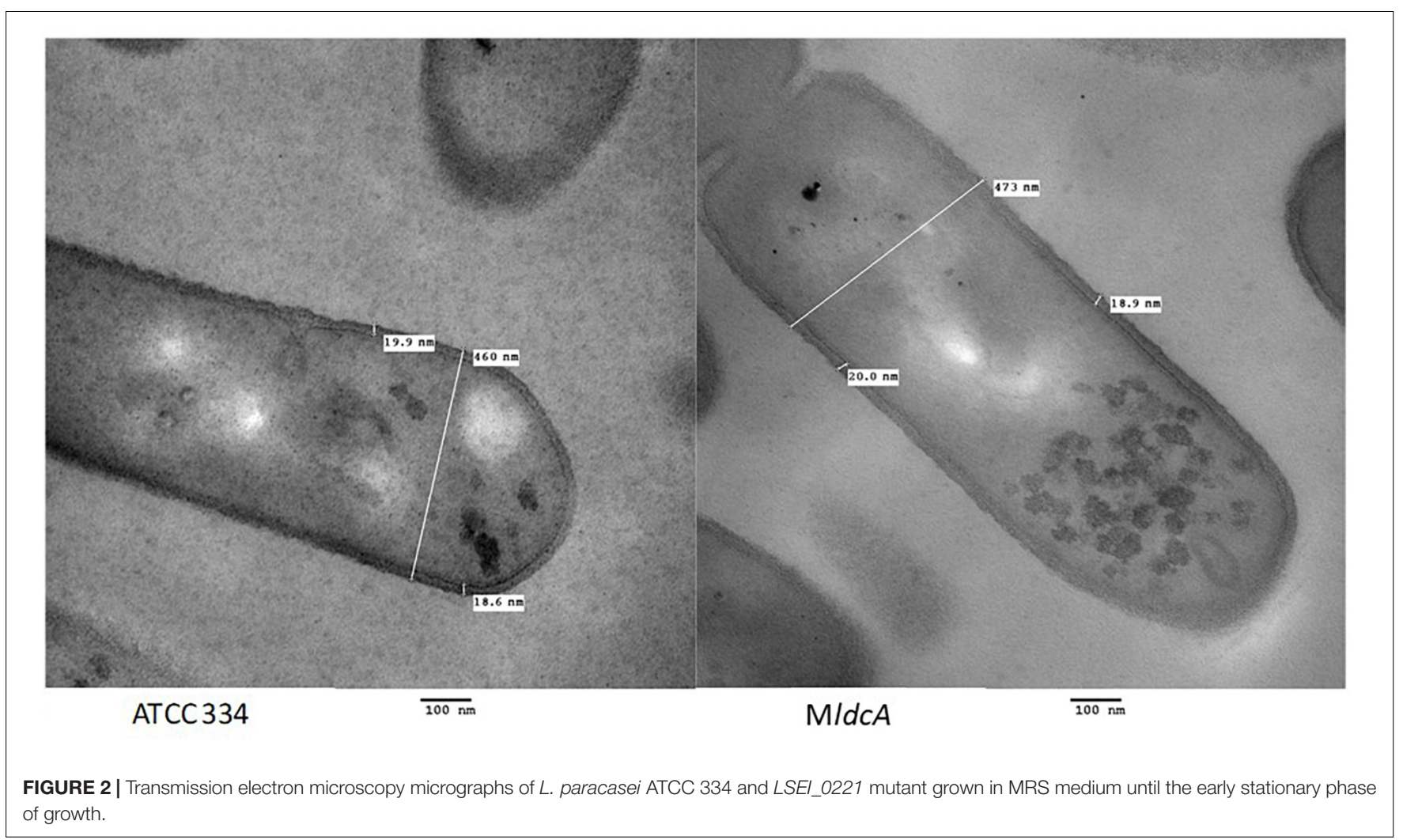

(Perpetuini et al., 2016). Thus, these properties were evaluated for the MldcA mutant and compared to the ATCC 334.

The MICs of four antimicrobials (penicillin, bacitracin, nisin, and vancomycin), which inhibit PG biogenesis at different steps, were determined (Figure $\mathbf{4 A}$ ). As the MldcA mutant was not more susceptible to vancomycin than the ATCC 334, we concluded that the altered PG of the mutant still contained pentadepsipeptides ending with D-Ala-D-Lac (Handwerger et al., 1994; Billot-Klein et al., 1997). On the contrary, the mutant displayed an increased susceptibility to penicillin, bacitracin, and nisin. The increased susceptibility to penicillin corresponded to the expected phenotype for a PBP defective mutant. The increased bacitracin susceptibility suggested a slower renewal of PG since this antibiotic inhibits undecaprenyl phosphate regeneration, an indispensable step to synthesize new PG strains. The nisin acts as a membrane disturber. The reason why M $l d c A$ mutant was more susceptible to nisin than ATCC 334 could be an easier passage of nisin through the cell wall, most likely due to a change in surface polarity and/or by a slower renewal of PG (nisin binds lipid II and inhibits PG synthesis).

Thus, bacterial surface properties were assessed by MATS tests on the MldcA mutant, ATCC 334, and MdltA mutant (LSEI_0794). The MdltA mutant is altered in teichoid acid Dalanylation, a function that contributes to reduce the negative net charge of the cell wall surface (Neuhaus and Baddiley, 2003). The MATS values indicate that $L$. paracasei ATCC 334 surface displays basic, acidic, and hydrophobic properties in agreement with previous observations (Munoz-Provencio et al., 2009) (Figure 4B). The MdltA mutant displays a higher surface hydrophobicity than ATCC 334. Surface properties of the MldcA mutant are the same as the ATCC 334. Thus, PG modifications in the $\mathrm{M} l d c A$ mutant do not impact surface properties and do not seem to alter teichoic acid presentation at the cell surface.

Autolysis profiles were assessed by exposing bacterial cells to Triton X-100, a detergent known to remove the LTA. LTA acts as an inhibitor on the general bacterial autolytic system (endogenous autolysins) (Raychaudhuri and Chatterjee, 1985). As a Lactobacillus rhamnosus GG $\Delta d l t D$ mutant has been reported to display an increased autolysis (Perea Velez et al., 2007), the L. paracasei MdltA mutant was also submitted to this autolysis test for comparison. The M $l d c A$ mutant exhibited higher Triton X-100-induced autolysis rates than the ATCC 334 strain (Figure 4C). This autolysis rate was similar to the MdltA mutant during the first $2 \mathrm{~h}$ and was even higher after. This observation suggested either a higher recruitment of autolysins in this mutant, despite a correct teichoic acid presentation, or the structure of the PG renders it more susceptible to autolysin activity.

\section{Functionality of the CwaRS TCS in vitro}

The $c w a R$ gene was overexpressed in E. coli, and the resulting CwaR protein was purified. CwaR size analyzed by SDSPAGE was consistent with that expected $(27 \mathrm{kDa})$ (Figure 5A). Incubation of purified CwaR with ${ }^{32} \mathrm{P}$ radiolabeled acetylphosphate showed that CwaR was able to autophosphorylate using acetyl phosphate, a molecule which is a common phosphate donor (Figure 5A). The cytosolic domain of CwaS, named cCwaS, corresponding to residues 137-396 of the CwaS protein, 


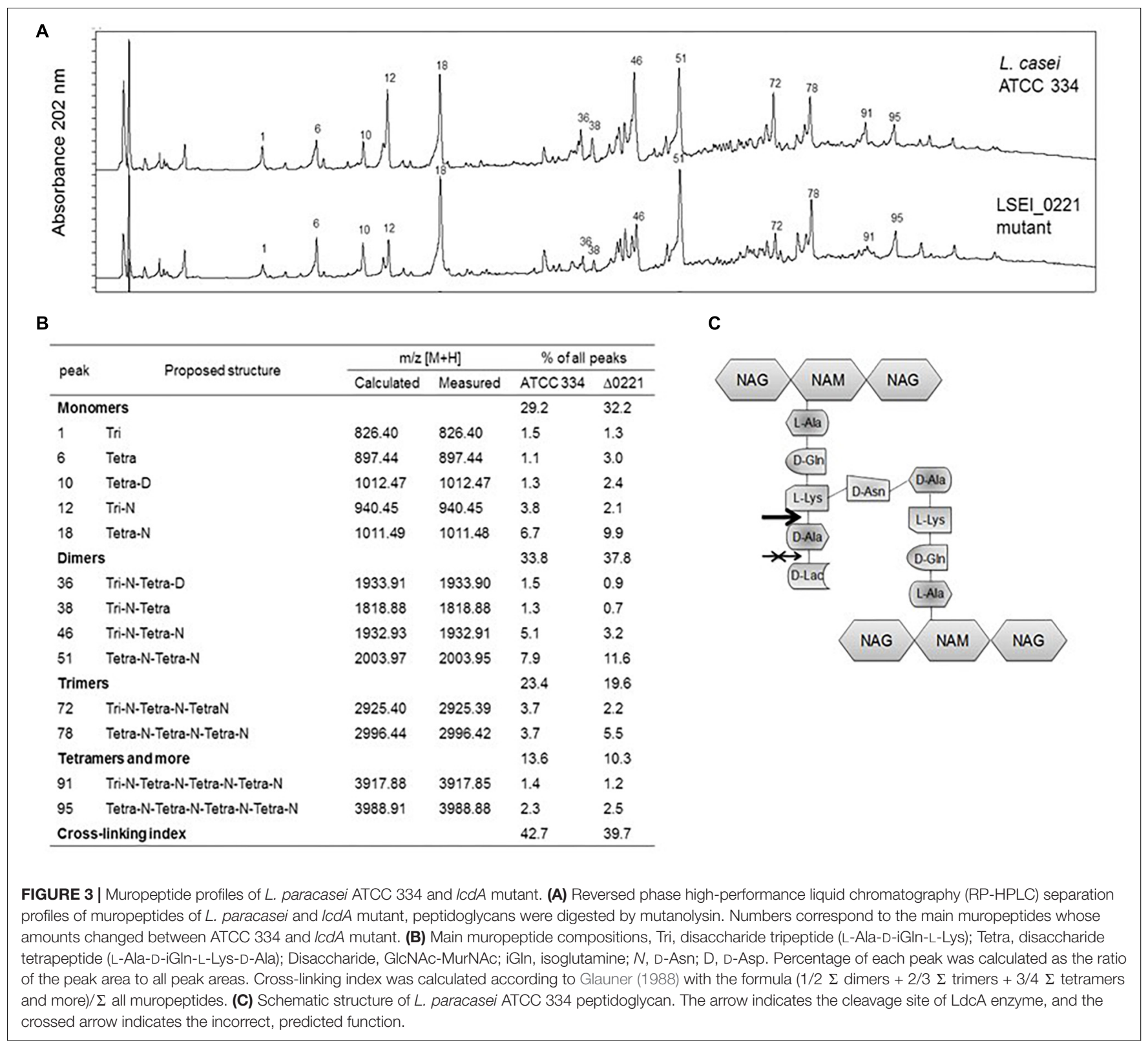

was overexpressed in E. coli, purified and a $29-\mathrm{kDa}$ protein was obtained. It was able to autophosphorylate using $\left[\gamma_{-}{ }^{32} \mathrm{P}\right]-$ ATP as the phosphate donor which confirms the predicted kinase function (Figure 5B). To visualize if CwaS-R can function together as a TCS in vitro, the radiolabeled phosphorylated cCwaS was incubated with the purified CwaR. A partial dephosphorylation of the cCwaS and a phosphorylation of the CwaR were visible, demonstrating that the $\mathrm{c} C w a S$ was able to transfer phosphate to the CwaR (Figure 5B). The loss of the ${ }^{32} \mathrm{P}$ from cCwaS-P was much greater than the gain of ${ }^{32} \mathrm{P}$ on CwaR, but it is an in vitro experiment and the phosphorylation rate is not $100 \%$. The predicted binding phosphate residues are His163 for CwaS and Asp52 for CwaR (determined by in silico analysis).

EMSAs were carried out with the promoter of the cwaRS$l d c A$ operon for two purposes. The first was to complete the demonstration of the functionality of the TCS in vitro. The second was to determine whether the TCS satisfies the observation that, when part of an operon, it is generally able to act on its own promoter and to autoregulate the whole operon (Stock et al., 2000). The phosphorylated and unphosphorylated forms of the purified CwaR protein were incubated individually with a 443-bp probe, named PromcwaR, corresponding to the whole LSEI_0218-cwaR intergenic region for EMSA. Despite all our attempts using different experimental conditions (binding buffer, freshly prepared CwaR, phosphorylated or unphosphorylated, ...), no interaction between the PromcwaR probe and the purified RR could be observed (data not shown). The failure of EMSA with the purified CwaR could be due to CwaR misfolding during protein production, to non-adapted buffer conditions, or the lack of a co-factor or protein partner. Thus, EMSAs were 
A

\begin{tabular}{|c|c|c|c|c|c|c|c|c|c|c|c|}
\hline \multirow[b]{2}{*}{ ATCC 334} & \multicolumn{3}{|c|}{ Penicillin } & \multicolumn{3}{|c|}{ Bacitracin } & \multicolumn{3}{|c|}{ Nisin } & \multicolumn{2}{|c|}{ Vancomycir } \\
\hline & 0.1 & $<M I C<$ & 0.2 & 200 & $<\mathrm{MIC}<$ & 400 & 10 & $<M I C<$ & 20 & 500 & $<M I C<$ \\
\hline IdcA mutant & 0.05 & $<M I C<$ & 0.1 & 50 & $<M I C<$ & 100 & 5 & $<M I C<$ & 10 & 500 & $<M I C<$ \\
\hline
\end{tabular}

B

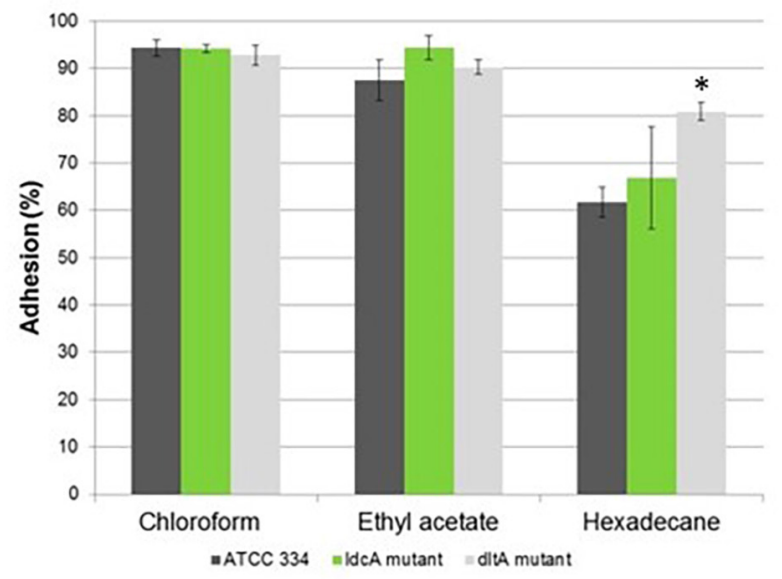

C

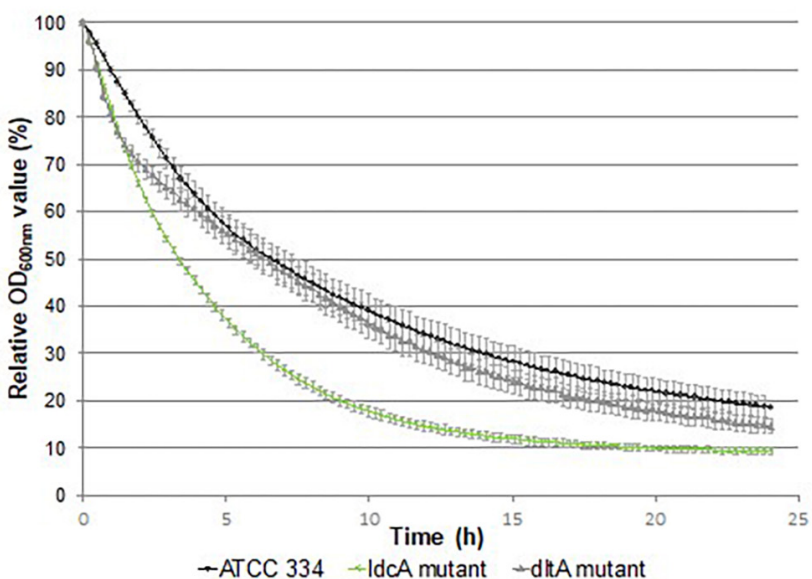

FIGURE 4 | Analysis of surface properties of ATCC 334 and IdcA mutant of L. paracasei. (A) Minimal inhibitory concentration (MIC) of ATCC 334 and the /dcA mutants in $\mu \mathrm{g} \cdot \mathrm{ml}^{-1}$. (B) Microbial Adhesion To Solvents (MATS) tests of ATCC 334 and the ldcA and dltA mutants. Error bars represent standard deviations between three biological repeats. Statistical analysis was performed for each mutant versus ATCC334 using the unpaired Student $t$ test: ${ }^{*} P<0.01$. (C) Autolysis profiles of ATCC 334 and the IdcA and dltA mutants. Cultures were grown to the exponential phase of growth (OD of 0.8 ), then the cells were pelleted and suspended in phosphate-buffered saline (PBS) containing $0.05 \%$ Triton X-100 (v/v) and incubated at $30^{\circ} \mathrm{C}$. Error bars represent standard deviations between three biological repeats.

carried out using crude cytosolic protein extracts of L. paracasei ATCC 334 (containing both CwaS and CwaR proteins), of McwaR mutant (containing CwaS-probably at a smaller level than ATCC 334 because of the alteration of transcription demonstrated before-but not CwaR) and of the McwaS mutant (containing CwaR but not CwaS protein) (Figure 5C). The PromcwaR probe was shifted when protein extracts from ATCC 334 and the McwaS mutant were used, but not by those from the McwaR mutant, for the same cytosolic proteins concentration (Figure 5D). Thus, CwaR is able to bind the promoting region of the operon in conditions that could not be replicated in vitro with the purified CwaR. It acts as the transcriptional regulator of its operon, and it needs some additional cellular elements and/or a protein co-factor to be active at this DNA site.

\section{Consequences of cwaR, cwaS, and IdcA Gene Inactivation on the Regulation of Genes Involved in Peptidoglycan Synthesis}

Transcriptomic analysis of 50 PG-related genes in McwaR, Mcwas, and MldcA mutants compared to ATCC 334 was carried out in exponential and stationary phases of growth for two main purposes: (i) determining if the lack of LdcA was partly compensated by another enzyme and (ii) identifying the possible PG-related genes regulated by the CwaRS TCS. Only two genes were upregulated in the MldcA mutant: LSEI_0393 (for exponential phase only) and LSEI_0539 (Figure 6A and Supplementary Table S2). LSEI_0539 encodes a cell wallassociated hydrolase with an NLPC-P60 and a glucosamidase domain; it could act as an $N$-acetylglucosamidase or an endopeptidase (Layec et al., 2008). LSEI_0393 encodes a 1,4beta- $N$-acetylmuramidase with a glyco_hydro_25 and a LysM domain (Layec et al., 2008). These proteins may bring functional compensation of the LdcA absence. These upregulations could explain the higher rate of autolysis in mutant. Overall, only a few PG-related genes were differentially transcribed in exponential phase, whereas many of these genes were downregulated in the stationary phase of growth in the McwaR mutant, and even more in MldcA mutant, as though gene regulation was directed to slow down the turnover of PG. The strongest downregulated genes in all mutants were LSEI_0020,LSEI_2029, and LSEI_2226 (Figure 6A). LSEI_2029 and LSEI_2226 encode predicted cell wall-associated hydrolases. The downregulation of genes in the stationary phase was generally less important in McwaS mutant than in McwaR mutant, suggesting that the regulator responds to other sensors. By searching the differences of relative transcript levels between $\mathrm{McwaR}$ mutant (inactivated TCS and lack of LdcA) and MldcA mutant (functional TCS and inactivated LdcA), we propose 17 candidate genes to be regulated by the CwaRS TCS. They can be split into two subgroups: (i) those that are differently expressed in the MldcA mutant 


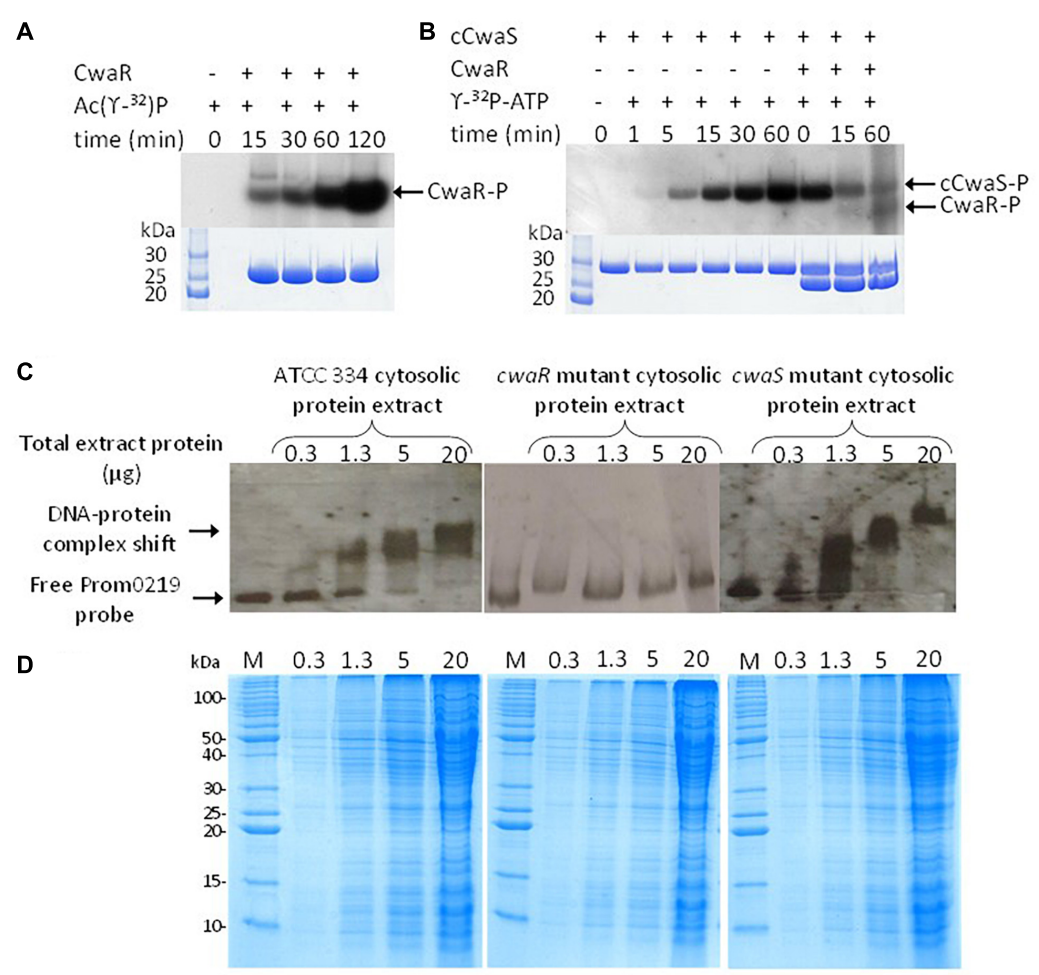

FIGURE 5 | In vitro characterizations of the two-component system (TCS). (A) Radiolabeling of RR0219 using [ $\left.\gamma-{ }^{32} \mathrm{P}\right]$ acetyl phosphate after different times of incubation. (B) Autophosphorylation of the cytosolic domain of HKO220 (cHKO220) when incubated with $\left[\gamma\right.$ - ${ }^{32}$ P]ATP. After an incubation of 60 min, the RR0219 protein was added, and the phosphotransfer from radiolabeled cHK0220 (CHK0220-P) to RR0219 was observed after different times of co-incubation.

(C) Electrophoretic mobility shift assay (EMSA) of $c$ waR promoter with cellular extract of $L$. paracasei ATCC 334 and the cwaR mutant. (D) The corresponding sodium dodecyl sulfate-polyacrylamide gel electrophoresis (SDS-PAGE) is $12.5 \%$.

(LSEI_0539, LSEI_0810, LSEI_0906, LSEI_1089, LSEI_12691272, LSEI_1314, LSEI_1802, and LSEI_2570), meaning a ldcAdependent regulation ( $l d c A$ regulation influences the regulation of other genes), and (ii) those that are differently expressed in the McwaR mutant (LSEI_0223, LSEI_0251, and LSEI_0435), meaning a $l d c A$-independent regulation (Figure 6A). LSEI_0393 and LSEI_1909 belong to the genes possibly regulated by the TCS but, since their expression profiles varied between exponential and stationary phases, they cannot be classified in these subgroups. The 10 other genes whose transcription changed were regulated in a CwaRS TCS-independent manner (Figure 6A), meaning the involvement of additional regulatory system(s) in response to the lack of LdcA. Also, among all the tested genes, 23 were transcribed at similar levels whatever the condition (Supplementary Figure S1 and Supplementary Table S2).

\section{Impact of cwaR, cwaS, and IdcA Gene Inactivation on the Surface Proteins}

Surface protein isolations by $\mathrm{LiCl}$ extraction were carried out for ATCC 334, McwaR, McwaS, and MldcA mutants and analyzed by SDS-PAGE (Figure 6B). In accordance with genome annotation, no S-layer proteins were found. In the three mutant profiles, two bands, corresponding to proteins of about $40 \mathrm{kDa}$, were fivefold lower than in the ATCC 334 strain (Figure 6B). Protein sequence analysis of these spots revealed that they corresponded to LSEI_0020 and LSEI_2029 proteins, both annotated as surface antigens. This decrease was consistent with the downregulation of LSEI_0020 and LSEI_2029 genes in mutants (see above). The protein encoded by LSEI_0020 is orthologous to Msp2 (also named p40) of L. rhamnosus GG (Yan et al., 2013) and L. casei BL23 (85 and 95\% identities, respectively). The LSEI_2029 protein shares $72 \%$ identity with LGG_02016, a surface antigen (NLP/P60) of L. rhamnosus. The N-terminal part of LSEI_2029 protein sequence presents $46 \%$ identity with the 224 first amino acids of LSEI_0020, whereas the C-terminal part presents 50\% identity with the 112 amino acids of the C-terminal part of LSEI_0281, the Msp1 (p75) ortholog. The other differences in protein profiles between ATCC 334 and mutants correspond mainly to intracellular proteins which could be more easily released from mutants because of an increased susceptibility to the extraction procedure.

\section{Impact of Gene Inactivation on Some Deleterious Factors Characterizing the Gut}

Adhesion to eukaryotic components is a bacterial strategy to escape gut transit and interact with the gut. Thus, $L$. paracasei ATCC 334 and McwaR, McwaS, and MldcA mutants were tested 
A

\begin{tabular}{|c|c|c|c|c|c|c|c|}
\hline \multirow[b]{3}{*}{ Gene } & \multirow[b]{3}{*}{ Predicted product } & \multicolumn{6}{|c|}{ Fold change in expression } \\
\hline & & \multicolumn{3}{|c|}{ Exponential phase } & \multicolumn{3}{|c|}{ Stationary phase } \\
\hline & & $\begin{array}{l}\text { CWoR } \\
\text { mutant }\end{array}$ & $\begin{array}{l}\text { cwos } \\
\text { mutant }\end{array}$ & $\begin{array}{c}\text { IdcA } \\
\text { mutant }\end{array}$ & $\begin{array}{l}\text { CWoR } \\
\text { mutant }\end{array}$ & $\begin{array}{l}\text { cwos } \\
\text { mutant }\end{array}$ & $\begin{array}{c}1 d C A \\
\text { mutant }\end{array}$ \\
\hline LSEI_0020 & surface antigen & -1.30 & -1.21 & -1.34 & $-2.52^{\circ}$ & $-2.75^{\circ}$ & -5.34 \\
\hline LSEI_0249 & cell wall-associated hydrolase & -2.06 & $-2.24^{b}$ & -1.66 & $-2.23^{\circ}$ & $-2.60^{\mathrm{b}}$ & -2.31 \\
\hline LSEI_0599 & 1,4-beta- $\mathrm{N}$-acetylmuramidase & +1.03 & +1.23 & +1.24 & $-2.25^{\circ}$ & -1.72 & $-2.53^{b}$ \\
\hline LSEI_1072 & 1,4-beta- $\mathrm{N}$-acetylmuramidase & -1.38 & -1.36 & -1.21 & $-2.07+$ & -1.90 & $-2.41^{\circ}$ \\
\hline LSEI_1116 & $\mathrm{N}$-acetyImuramidase & -1.77 & -1.52 & -1.30 & -2.37 & -1.85 & $-2.39^{\mathrm{b}}$ \\
\hline LSEI_1481 & membrane carboxypeptidase & -1.74 & -1.81 & -1.20 & $-2.50^{5}$ & -2.05 & $-2.51^{b}$ \\
\hline LSEI_1662 & cell division protein FtsI & -2.12 & -1.66 & -1.23 & -2.17 & -1.60 & $-2.03^{b}$ \\
\hline LSEI_1725 & membrane carboxypeptidase & -1.33 & -1.28 & 1.14 & -2.24 & -1.77 & $-2.45^{\circ}$ \\
\hline LSEI_2029 & surface antigen & -1.44 & -1.75 & -1.51 & $-2.9^{b}$ & $-4.28^{b}$ & $-5.02^{b}$ \\
\hline LSEI 2226 & cell wall-associated hydrolase & $-2.29^{\mathrm{b}}$ & -1.88 & -1.73 & $-2.76^{\circ}$ & $-3.87^{\mathrm{b}}$ & $-3.98^{\mathrm{b}}$ \\
\hline LSEI_0S39 & cell wall-associated hydrolase & +1.02 & +1.16 & +4.2 & -1.32 & -1.42 & $+2.93^{b}$ \\
\hline LSEI_0810 & membrane carboxypeptidase & -1.27 & -1.14 & -1.23 & -1.73 & -1.62 & $-2.25^{\mathrm{b}}$ \\
\hline LSEI_0906 & undecaprenyl pyrophosphate phosphatase & -1.54 & -1.24 & -1.24 & -2.01 & -1.67 & $-2.74^{b}$ \\
\hline LSEI_1089 & glycosyltransferase-like protein & -1.21 & 1.06 & -1.45 & -1.99 & -1.81 & $-2.61^{b}$ \\
\hline LSEI_1269 & cell division protein FtsI & -1.33 & -1.13 & -1.24 & -1.72 & -1.48 & $-2.05^{t}$ \\
\hline LSEI_1270mraY & phospho-N-acetylmuramoyl-pentapeptide-transferase & -1.34 & -1.14 & -1.20 & -1.81 & -1.50 & $-2.19^{\circ}$ \\
\hline LSEI_1271murD & UDP-N-acetylmuramoyl-L-alanyl-D-glutamate synthetase & -1.22 & -1.18 & -1.11 & -1.74 & -1.43 & -2.31 \\
\hline LSEI_1272murG & $\begin{array}{l}\text { undecaprenyldiphospho-muramoylpentapeptide beta- } \mathrm{N} \text { - } \\
\text { acetylglucosaminyltransferase }\end{array}$ & -1.17 & -1.35 & -1.25 & -1.61 & -1.40 & -2.17 \\
\hline LSEI_1314 & cell division membrane protein & +1.10 & +1.35 & -1.22 & -1.62 & -1.52 & $-2.42^{b}$ \\
\hline LSEI_1802 & beta-lactamase class $\mathrm{C}$ related penicillin binding protein & -1.07 & -1.15 & +1.09 & -1.65 & -1.61 & $-2.06^{\mathrm{t}}$ \\
\hline LSEI_25S0 & hypothetical protein & -1.24 & -1.15 & -2.81 & -1.45 & -1.18 & $-3.76^{\circ}$ \\
\hline LSEI 2570 & UDP-N-acetylglucosamine 1-carboxyvinyltransferase & -1.16 & -1.26 & -1.09 & -1.68 & -1.54 & $-2.14 t$ \\
\hline LSEI_0393 & 1,4-beta- $\mathrm{N}$-acetylmuramidase & +1.10 & +1.01 & $+2.24^{\circ}$ & $-2.02^{b}$ & -1.84 & 1.22 \\
\hline LSEI_1909 & 1,4-beta- $\mathrm{N}$-acetylmuramidase & $-2.82^{\mathrm{b}}$ & .2 .23 & -1.89 & -1.17 & -1.03 & $-2.58 \mathrm{~b}$ \\
\hline LSEI_0223murE & $\begin{array}{l}\text { UDP-N-acetylmuramoylalanyl-D-glutamate- }-2,6 \\
\text { diaminopimelate ligase }\end{array}$ & -1.33 & +1.22 & -1.07 & $-2.15^{b}$ & -1.24 & -1.84 \\
\hline LSEI_0251 & glycosyltransferase-like protein & -1.72 & +1.42 & +1.21 & $-2.32^{b}$ & -1.10 & -1.24 \\
\hline LSEI_0.335 & beta-lactamase class C related penicillin binding protein & $-2.66^{\circ}$ & -2.44 & -1.18 & +1.04 & +1.17 & +1.08 \\
\hline
\end{tabular}

B

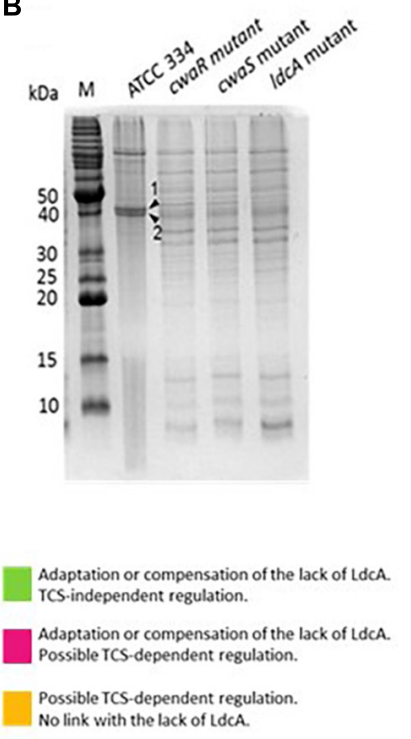

FIGURE 6 | Consequences of cwaRS gene inactivation on genes encoding in peptidoglycan (PG) synthesis proteins and surface proteins. (A) Transcriptional profiles for genes implicated in PG synthesis of the McwaR, McwaS, and M/dcA mutants relative to the parental strain ATCC 334 grown either exponential or stationary phase. Values are the mean RTL obtained for three biological repeats. In bold letters, significant values; in red and ${ }^{\mathrm{a}}$, upregulation, $p<0.01$; in light red and ${ }^{\mathrm{b}}$, upregulation, $p<0.05$; in blue and ${ }^{a}$, downregulation, $p<0.01$; in light blue and ${ }^{b}$, downregulation, $p<0.05$. Genes for which no significant value was obtained are not presented. The list of the tested genes and their corresponding annotations are presented in Supplementary Table S2. (B) Sodium dodecyl sulfate-polyacrylamide gel electrophoresis (SDS-PAGE) of surface protein extracts from L. paracasei ATCC 334 and McwaR, McwaS, and M/dcA mutants in stationary phase of growth. (1) Surface antigen (LSEI_2029), (2) Surface antigen (LSEI_0020).

for their ability to adhere to polystyrene coated with mucin. Adhesion to mucin was similar for the ATCC 334 and mutant strains (Supplementary Figure S2). Thus, the change in PG composition and the decrease of surface antigens did not impact the mucin adhesion ability of $L$. paracasei.

The resistance of the three mutants to stresses encountered in the ileum was assessed by competition with ATCC 334 in the following conditions: (i) low-nutrient, acidic ( $\mathrm{pH} 3.5$ ); (ii) low-nutrient, bile-supplemented ( 3 g.l $\left.\mathrm{l}^{-1}\right)$; and (iii) low-nutrient, lysozyme-supplemented $\left(10 \mathrm{g.l}^{-1}\right)$ (Figure $\left.7 \mathrm{~A}\right)$. The three mutants are not equal regarding stress resistance. The McwaR mutant was less resistant than ATCC 334 for all the conditions tested, contrary to McwaS and MldcA mutants which did not display any significant change compared to ATCC 334 . These results demonstrated that, taken separately, ileal physicochemical conditions are not enough to decrease the survival of the three mutants. They also suggest a specific involvement of the CwaRS TCS in response to stress, regardless of cell surface modifications. This proposal was confirmed by measuring the relative transcript level of the $c w a R$ gene, taken as a reporter for the involvement of CwaRS during stress responses. Ten abiotic stresses were applied to ATCC 334 (penicillin, vancomycin, $\mathrm{HCl}$, lactate, ethanol, $\mathrm{NaCl}$, bile, heat, cold, SDS) as described in the section "Materials and Methods." Transcript levels of cwaR increased when vancomycin or bile were added in the medium and also during a hot thermal stress, whereas transcript levels decreased in the presence of SDS, compared to the non-stressful reference condition (Figure 7B).
Thus, the CwaRS TCS could be recruited during gut transit in response to bile.

The effect of antimicrobial peptides, hBD1, hBD2, LL37, and CCL20 on the three mutants and L. paracasei ATCC 334 was assessed (Figure 7C). The MdltA, MdltC, and MdltD mutants were added to this test as predicted susceptible mutants because LTA D-alanylation reduces the negative net charge of the cell wall surface, allowing the resistance against antimicrobial cationic peptides (Neuhaus and Baddiley, 2003). None of the mutants displayed an increased susceptibility to LL37. All mutants (except MdltA) were more susceptible to hBD2 than ATCC334. Moreover, the McwaR, McwaS, and MldcA mutants were susceptible to hBD1 and CCL20. The MldcA mutant was even more susceptible to hBD1 and hBD2 than the other mutants. The three mutants of the operon were at least eight-fold more susceptible to hBD1 than the ATCC 334 and at least six-fold more susceptible to hBD2 and CCL20. The antimicrobial cationic peptide susceptibility could be responsible for the decreased survival of the mutants observed in the ligated rabbit ileal loop (Licandro-Seraut et al., 2014).

\section{DISCUSSION}

The symbiotic balance of the host with its microbiome is based on the regulation of the microbiota by the host immune system, and inversely of the immune system by its microbiota. 
A

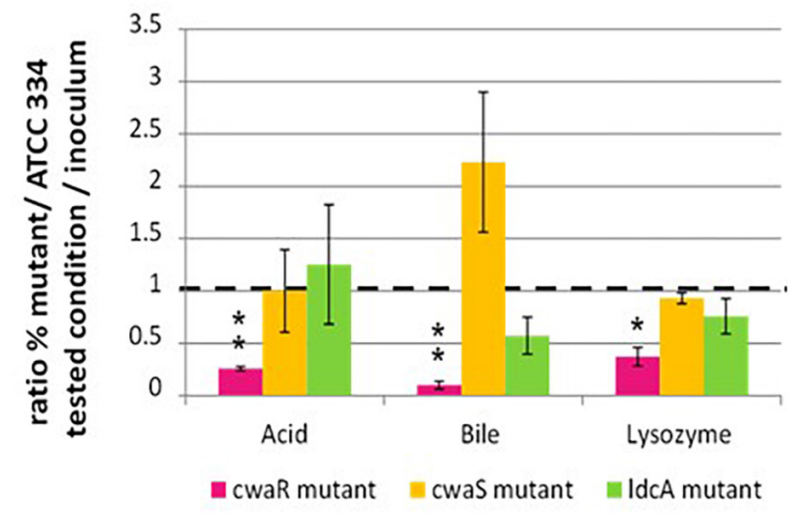

B

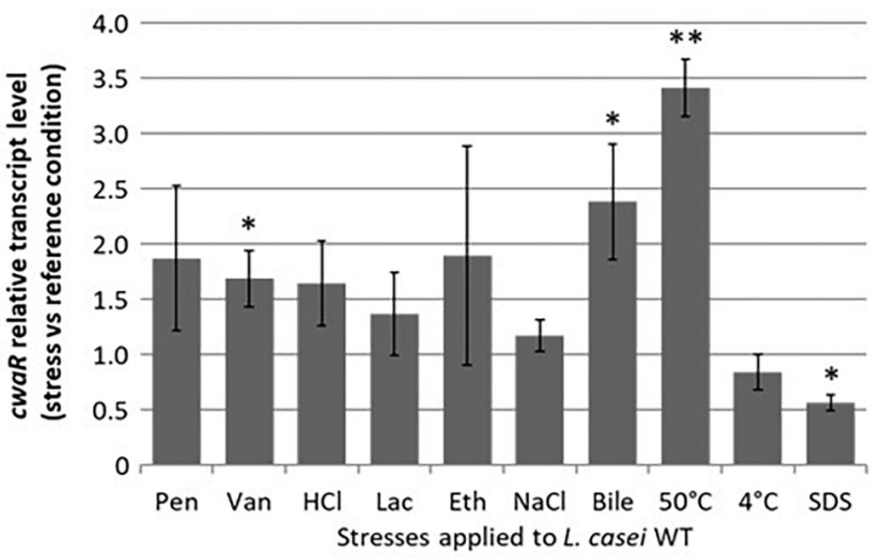

C

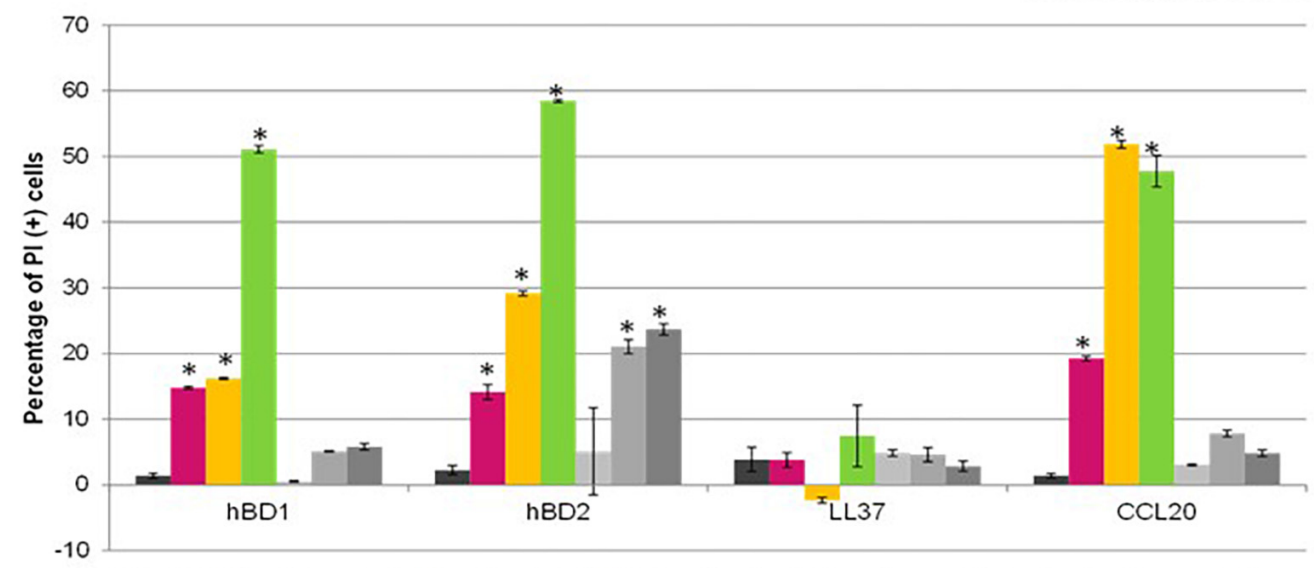

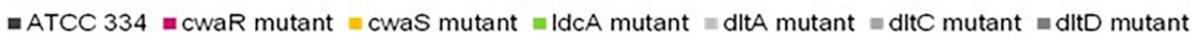

FIGURE 7 | Role of cwaSR genes in adaptation to gut conditions and to reference stresses. (A) Competition in stressful conditions between $L$. paracasei mutants (McwaR, McwaS, and M/dcA) and ATCC 334. The competitions were carried out in diluted MRS broth (1/20) in $16 \mathrm{~h}$ at $37^{\circ} \mathrm{C}$; acid pH 3.5; bile $3 \mathrm{~g} . \mathrm{I}^{-1}$; lysozyme $10 \mathrm{~g} . \mathrm{l}^{-1}$. The percentage was determined by counting on Petri dishes. Three biological repeats were performed, and bars indicate standard deviations. Statistical analysis was performed using the unpaired Student $t$-test: ${ }^{*} P<0.01 ;{ }^{* *} P<0.001$. (B) Relative transcript levels of $c$ waR gene in $L$. paracasei ATCC 3334 under stressful conditions. L. paracasei was grown until OD reached 0.6. Then, a 15-min stress was applied. Transcript levels are expressed as the relative fold change, with $L$. paracasei cells incubated at $37^{\circ} \mathrm{C}$ as the reference condition (fold change $=1$ ). Pen, penicillin $0.1 \mu \mathrm{g} / \mathrm{ml}$; Van, vancomycin $0.5 \mathrm{mg} / \mathrm{ml} ; \mathrm{HCl}, \mathrm{HCl}$ added to reach pH 3; Lac, lactic acid added to reach pH 3; Eth, ethanol 15\% (vol/vol); NaCl, NaCl 1 M; Bile, bile $3 \mathrm{~g} /$; SDS, SDS 0.5 g/l. Four biological repeats were performed, and bars indicate standard deviations; * $p<0.05 ;{ }^{* *} p<0.01$. (C) Percentage of PI (+) bacteria (permeabilized cell) after treatment with hBD1, hBD2, LL37, and CCL20. Values were obtained by flow cytometry. * Indicate significant differences $(P<0.05)$.

Actors responsible for the regulation of the microbiota are increasingly well understood (cationic peptides, cathelicidin, ...). The different species that comprise the microbiota must resist these different attacks, and also the stressful conditions of the gut. The cwaRS-ldcA operon of L. paracasei ATCC 334 is required to maintain the bacterium in the gut (Licandro-Seraut et al., 2014).

PG composition analysis suggests that LdcA enzyme acts as an L,D-carboxypeptidase, and not as a D-Ala-D-Ala carboxypeptidase. The same difference between predictive and empiric functions was observed for DacB of Lactococcus lactis (Courtin et al., 2006). Also, the inactivation of $l d c A$ did not alter cell morphology, contrary to what was observed for other PG hydrolases such as LSEI_0281 (Licandro-Seraut et al., 2014), a gene whose orthologs, p75 and msp1, have been studied in L. casei BL23 and in L. rhamnosus GG, respectively (Claes et al., 2012;
Regulski et al., 2012). Moreover, according to our observations, PG thickness was unchanged in the MldcA mutant.

The $c w a R S$ genes (encoding the TCS) are in an operon with the $l d c A$ gene, so we hypothesized that they were related to cell wall biogenesis regulation. This assumption was confirmed by transcriptomic analysis. The CwaRS TCS is able to regulate the expression of 17 cell wall-related genes including genes encoding enzymes dedicated to lipid II synthesis. On the other hand, CwaRS TCS-independent genes encode mainly enzymes dedicated to PG assembly. This is probably the consequence of PG architecture modifications due to the inactivation of the LdcA enzyme. In addition to its cell wall-related function, the CwaRS TCS is required to resist several stresses since the McwaR mutant was less able to survive in bile, acid, or lysozyme than ATCC 334 or the $\mathrm{M} l d c A$ mutant. This particular phenotype is consistent 
with previous reports on $L$. casei (Alcantara et al., 2011). The best candidate for the regulation of CwaRS TCS-independent genes is the LSEI_2808-2807 TCS because it is structurally close to the WalKR TCS, a TCS playing a role in cell wall metabolism in other bacterial genera (Bisicchia et al., 2007; Dubrac et al., 2007; Delaune et al., 2011).

A global downregulation of predicted PG hydrolases was observed in the MldcA mutant, particularly during the stationary phase of growth. It can be assumed that this mutant required less PG hydrolases because of its PG structure (absence of relevant muropeptide substrate) or because of a lower PG turnover. The genes LSEI_0020, LSEI_2029, and LSEI_2226 encode PG hydrolases with no predicted specificity. LSEI_2226 Nterminal domain is homologous to the L. rhamnosus putative cell wall hydrolase LGG_02225. These genes presented the strongest downregulations in the MldcA mutant. As they are similarly downregulated in the TCS mutants (McwaR and McwaS mutants), which are more susceptible to stress than the $\mathrm{M} l d c A$ mutant, their lower transcriptions cannot be correlated with resistance to stress. Nevertheless, a differential posttranscriptional regulation between mutants cannot be excluded. Indeed, PG hydrolase activity can be modulated by their own O-glycosylation (Lebeer et al., 2012; Rolain et al., 2013) or by PG modifications such as NAG O-acetylation (Bernard et al., 2011), NAG $N$-acetylation (Meyrand et al., 2007), or by teichoic acid D-alanylation (Steen et al., 2005; Palumbo et al., 2006).

We assumed that the change in PG structure would also affect the barrier function of the cell wall. Above all, for the mutants, the two surface antigens (LSEI_0020 and LSEI_2029) are less abundant at the surface. This can be explained by a decrease of gene expression and/or by an alteration of the anchoring at the PG layer. The first proposal is validated for both genes. The protein encoded by LSEI_0020 is the ortholog of $p 40$ (or $m s p 2$ ) that can bind mucin (Bauerl et al., 2010). Nevertheless, in our conditions, no statistically significant differences between mutants and ATCC 334 were observed for adhesion to mucin. In $L$. rhamnosus, several intestinal epithelium homeostasis-promoting functions were attributed to $\mathrm{p} 40$. The $\mathrm{p} 40$ protein can activate Akt [protein kinase $\mathrm{B}(\mathrm{PKB})]$, inhibit cytokine-induced epithelial cell apoptosis, induce colon epithelial cell growth, and decrease epithelial barrier damage induced by hydrogen peroxide (Yan et al., 2007; Seth et al., 2008). The protein encoded by LSEI_2029 is the ortholog of the L. rhamnosus LGG_02016 antigen (NlpC/P60 family) which is overexpressed in an acidic environment (Koponen et al., 2012). The mutant for LSEI_2029 is not altered in gut establishment in the rabbit ligated ileal loop model (Licandro-Seraut et al., 2014), suggesting that the decrease of LSEI_2029 antigen presentation alone is not enough to explain TCS and MldcA mutant phenotypes in the rabbit gut. It is interesting to note that in L. casei ATCC 393, there is no LSEI_2029 homolog, and the LBCZ_0019 (the LSEI_0020 homolog) expression is three times lower and predicted to be secreted (Johnson et al., 2016). The phenotype of the three mutants can be explained by either the change in PG composition or the decreased presentation of the two antigens, or the combination of these two changes to the L. paracasei cell surface architecture.

The MldcA mutant did not display an increased susceptibility to gut stresses currently tested, but the three $c w a R S$-ldcA mutants are more susceptible than ATCC 334 to hBD1, hBD2, and CCL20 antimicrobial peptides. Thus, the lack of LdcA modifies PG structure without changing the global surface charge, which increases susceptibility to AMPs. This phenomenon is independent of the functionality of CwaRS TCS. This could entirely explain the three mutant deficiencies in gut establishment. It makes sense regarding the mechanism of action of AMPs in Gram-positive bacteria. AMPs pass through the PG and inhibit PG synthesis. Indeed, PG precursors are activated and transported through the plasma membrane. The presence of AMP in the plasma membrane can disturb the translocation of these precursors and the PG organization (transglycosylation and transpeptidation) (Yeaman and Yount, 2003). L. paracasei ATCC 334 is resistant to hBD2, whereas L. rhamnosus GG and L. delbrueckii subsp. bulgaricus are susceptible (De Keersmaecker et al., 2006; Hugo et al., 2012). However, some other cell envelope changes could occur simultaneously, such as cell membrane structural changes in addition to PG alteration (which could also the sensitivity to nisin and AMPs). Indeed, PG structural perturbation may well be the result in a generalized cell envelope stress response which would be governed by other sensor/response systems in addition to this operon system and have a more global impact on gene expression. In this case, cell envelope stress response could be caused by structural damage.

Our results reinforce the importance of cell wall envelope in the host-microbe interaction and in bacterial adaptation to environmental changes since it is the foundation for an optimal cell wall structure (including cell wall-anchored proteins) (Sengupta et al., 2013; Delhaye et al., 2019). Deficiency in gut establishment for other L. paracasei mutants we have previously identified (Licandro-Seraut et al., 2014) could also result from PG modification: (i) the mutants for genes related to biogenesis of the cell wall (dlt operon, the LSEI_0238 and LSEI_2546 polysaccharide transporters); (ii) the ldhL1 (LSEI_2549) mutant which should be impacted in the production of lactate, a PG constituent (Ferain et al., 1996; Rico et al., 2008); (iii) the ansB (Asn synthase) mutant found in our screening which is reported to present an altered PG and to lose immune-activating capacity (Ito et al., 2014).

\section{CONCLUSION}

The cwaRS-ldcA operon is composed of a functional TCS involved in the regulation of PG synthesis and a PBP which acts as a putative L,D-carboxypeptidase instead of a D-Ala-D-Ala carboxypeptidase as predicted. This operon seems to be necessary for antigen presentation and for a suitable architecture of the bacterial surface. Hence, thanks to the CwaRS TCS and LdcA, L. paracasei cells are able to model their surface architecture in a manner that allows them to establish in the gut and to resist host defenses. 


\section{DATA AVAILABILITY STATEMENT}

All datasets generated for this study are included in the article/Supplementary Material.

\section{AUTHOR CONTRIBUTIONS}

HS, TP, IB, J-FC, PS, and HL contributed to study conception and design. HS, TP, AP, RW, and CP performed the experimentation and acquisition of data. HS and HL did the analysis and interpretation of data. HS drafted of manuscript. HL carried out critical revision. All authors read and approved the final manuscript.

\section{FUNDING}

This study was supported by the European Research Council Advanced Grant HOMEOEPITH to PS (Grant agreement no. 232798), the European Research Council Starting Grant PGNfromSHAPEtoVIR to IB (Grant agreement no. 202283), by the Regional Council of Bourgogne-Franche Comté, and the Fonds Européen de Developpement Régional (FEDER). PS is

\section{REFERENCES}

Abo-Amer, A. E., Munn, J., Jackson, K., Aktas, M., Golby, P., Kelly, D. J., et al. (2004). DNA interaction and phosphotransfer of the C4-dicarboxylateresponsive DcuS-DcuR two-component regulatory system from Escherichia coli. J. Bacteriol. 186, 1879-1889. doi: 10.1128/jb.186.6.1879-1889.2004

Alcantara, C., Revilla-Guarinos, A., and Zuniga, M. (2011). Influence of twocomponent signal transduction systems of Lactobacillus casei BL23 on tolerance to stress conditions. Appl. Environ. Microbiol. 77, 1516-1519. doi: 10.1128/aem. 02176-10

Arioli, S., Koirala, R., Taverniti, V., Fiore, W., and Guglielmetti, S. (2018). Quantitative recovery of viable Lactobacillus paracasei CNCM I-1572 (L. casei $\left.\mathrm{DG}^{\circledR}\right)$ after gastrointestinal passage in healthy adults. Front. Microbiol. 9:1720. doi: $10.3389 /$ fmicb.2018.01720

Arumugam, M., Raes, J., Pelletier, E., Le Paslier, D., Yamada, T., Mende, D. R., et al. (2011). Enterotypes of the human gut microbiome. Nature 473, 174-180.

Balandino, G., Milazzo, I., and Fazio, D. (2008). Antibiotic susceptibility of bacterial isolates from probiotic products available in Italy. Microbial. Ecol. Health Dis. 20, 199-203. doi: 10.1080/08910600802408111

Bauerl, C., Perez-Martinez, G., Yan, F., Polk, D. B., and Monedero, V. (2010). Functional analysis of the p40 and p75 proteins from Lactobacillus casei BL23. J. Mol. Microbiol. Biotechnol. 19, 231-241. doi: 10.1159/0003 22233

Bellon-Fontaine, M.-N., Rault, J., and van Oss, C. J. (1996). Microbial adhesion to solvents: a novel method to determine the electron-donor/electron-accpetor or Lewis acid-base properties of microbial cells. Colloids Surf B Biointerfaces 7 , 47-53. doi: 10.1016/0927-7765(96)01272-6

Bernard, E., Rolain, T., Courtin, P., Guillot, A., Langella, P., Hols, P., et al. (2011). Characterization of $\mathrm{O}$-acetylation of $\mathrm{N}$-acetylglucosamine: a novel structural variation of bacterial peptidoglycan. J. Biol. Chem. 286, 23950-23958. doi: 10. 1074/jbc.m111.241414

Billot-Klein, D., Legrand, R., Schoot, B., van Heijenoort, J., and Gutmann, L. (1997). Peptidoglycan structure of Lactobacillus casei, a species highly resistant to glycopeptide antibiotics. J. Bacteriol. 179, 6208-6212. doi: 10.1128/jb.179.19. 6208-6212.1997

Bisicchia, P., Noone, D., Lioliou, E., Howell, A., Quigley, S., Jensen, T., et al. (2007). The essential YycFG two-component system controls cell wall metabolism in a Howard Hughes Medical Institute foreign scholar. HS was supported by a grant from the Ministère de l'Enseignement Supérieur et de la Recherche.

\section{ACKNOWLEDGMENTS}

We thank the Pasteur Institute Microorganism Collection for the L. paracasei strain (CIP 107868 and ATCC 334). We wish to express particular thanks to Geraldine Lucchi and Patrick Ducoroy (CLIPP Clinical Innovation Proteomic Platform, IFR 100 Santé-STIC, Université de Bourgogne, Dijon, France) for carrying out protein identifications, and Jeannine Lherminier and Joël Michel (Centre de Microscopie INRA/uB, DimaCell Plateform, Dijon, France) for their advice and help regarding the TEM.

\section{SUPPLEMENTARY MATERIAL}

The Supplementary Material for this article can be found online at: https://www.frontiersin.org/articles/10.3389/fmicb. 2020.00156/full\#supplementary-material

Bacillus subtilis. Mol. Microbiol. 65, 180-200. doi: 10.1111/j.1365-2958.2007. 05782.x

Cai, H., Thompson, R., Budinich, M. F., Broadbent, J. R., and Steele, J. L. (2009). Genome sequence and comparative genome analysis of Lactobacillus casei: insights into their niche-associated evolution. Genome Biol. Evol. 1, 239-257. doi: 10.1093/gbe/evp019

Chapot-Chartier, M.-P., and Kulakauskas, S. (2014). Cell wall structure and function in lactic acid bacteria. Microbial. Cell Factories 13:S9.

Claes, I. J., Schoofs, G., Regulski, K., Courtin, P., Chapot-Chartier, M. P., Rolain, T., et al. (2012). Genetic and biochemical characterization of the cell wall hydrolase activity of the major secreted protein of Lactobacillus rhamnosus GG. PLoS One 7:e31588. doi: 10.1371/journal.pone.0031588

Clemente, J. C., Ursell, L. K., Parfrey, L. W., and Knight, R. (2012). The impact of the gut microbiota on human health: an integrative view. Cell 148, 1258-1270. doi: 10.1016/j.cell.2012.01.035

Cohen, S. N., Chang, A. C., and Hsu, L. (1972). Nonchromosomal antibiotic resistance in bacteria: genetic transformation of Escherichia coli by R-factor DNA. Proc. Natl. Acad. Sci. U.S.A. 69, 2110-2114. doi: 10.1073/pnas.69.8.2110

Courtin, P., Miranda, G., Guillot, A., Wessner, F., Mezange, C., Domakova, E., et al. (2006). Peptidoglycan structure analysis of Lactococcus lactis reveals the presence of an L,D-carboxypeptidase involved in peptidoglycan maturation. J. Bacteriol. 188, 5293-5298. doi: 10.1128/jb.00285-06

de Jonge, B. L., Chang, Y. S., Gage, D., and Tomasz, A. (1992). Peptidoglycan composition of a highly methicillin-resistant Staphylococcus aureus strain. The role of penicillin binding protein 2A. J. Biol. Chem. 267, $11248-11254$.

De Keersmaecker, S. C., Braeken, K., Verhoeven, T. L., Perea Velez, M., Lebeer, S., Vanderleyden, J., et al. (2006). Flow cytometric testing of green fluorescent protein-tagged Lactobacillus rhamnosus GG for response to defensins. Appl. Environ. Microbiol. 72, 4923-4930. doi: 10.1128/aem.02605-05

Delaune, A., Poupel, O., Mallet, A., Coic, Y. M., Msadek, T., and Dubrac, S. (2011). Peptidoglycan crosslinking relaxation plays an important role in Staphylococcus aureus WalKR-dependent cell viability. PLoS One 6:e17054. doi: 10.1371/ journal.pone.0017054

Delhaye, A., Collet, J. F., and Laloux, G. (2019). A Fly on the wall: how stress response systems can sense and respond to damage to peptidoglycan. Front. Cell Infect Microbiol. 9:380. doi: 10.3389/fcimb.2019.00380 
Di Renzo, T., Reale, A., Boscaino, F., and Messia, M. C. (2018). Flavoring production in kamut ${ }^{\circledR}$. quinoa and wheat doughs fermented by Lactobacillus paracasei, Lactobacillus plantarum, and Lactobacillus brevis: a SPME-GC/MS study. Front. Microbiol. 9:429. doi: 10.3389/fmicb.2018.00429

Dower, W. J., Miller, J. F., and Ragsdale, C. W. (1988). High efficiency transformation of $E$. coli by high voltage electroporation. Nucleic Acids Res. 16, 6127-6145. doi: 10.1093/nar/16.13.6127

Dubrac, S., Boneca, I. G., Poupel, O., and Msadek, T. (2007). New insights into the WalK/WalR (YycG/YycF) essential signal transduction pathway reveal a major role in controlling cell wall metabolism and biofilm formation in Staphylococcus aureus. J. Bacteriol. 189, 8257-8269. doi: 10.1128/jb.00645-07

Fehlbaum, S., Chassard, C., Schwab, C., Voolaid, M., Fourmestraux, C., Derrien, M., et al. (2019). In vitro study of Lactobacillus paracasei CNCM I-1518 in healthy and Clostridium difficile colonized elderly gut microbiota. Front. Nutr. 6:184. doi: 10.3389/fnut.2019.00184

Ferain, T., Hobbs, J. N. Jr., Richardson, J., Bernard, N., Garmyn, D., et al. (1996). Knockout of the two ldh genes has a major impact on peptidoglycan precursor synthesis in Lactobacillus plantarum. J. Bacteriol. 178, 5431-5437. doi: 10.1128/ jb.178.18.5431-5437.1996

Fiocco, D., Longo, A., Arena, M. P., Russo, P., Spano, G., and Capozzi, V. (2019). How probiotics face food stress: they get by with a little help. Crit. Rev. Food Sci. Nutr. 18, 1-29. doi: 10.1080/10408398.2019.1580673

Gensollen, T., Iyer, S. S., Kasper, D. L., and Blumberg, R. S. (2016). How colonization by microbiota in early life shapes the immune system. Science 352, 539-544. doi: 10.1126/science.aad9378

Gibson, T. J. (1984). Studies on the Epstein-Barr Virus Genome. PhD thesis, Cambridge University, Cambridge.

Girardin, S. E., Boneca, I. G., Viala, J., Chamaillard, M., Labigne, A., Thomas, G., et al. (2003). Nod2 is a general sensor of peptidoglycan through muramyl dipeptide (MDP) detection. J. Biol. Chem. 278, 8869-8872. doi: 10.1074/jbc. c200651200

Glauner, B. (1988). Separation and quantification of muropeptides with highperformance liquid chromatography. Anal. Biochem. 172, 451-464. doi: 10 . 1016/0003-2697(88)90468-X

Gury, J., Barthelmebs, L., Tran, N. P., Divies, C., and Cavin, J. F. (2004). Cloning, deletion, and characterization of PadR, the transcriptional repressor of the phenolic acid decarboxylase-encoding padA gene of Lactobacillus plantarum. Appl. Environ. Microbiol. 70, 2146-2153. doi: 10.1128/aem.70.4.2146-2153.2004

Gury, J., Seraut, H., Tran, N. P., Barthelmebs, L., Weidmann, S., Gervais, P., et al. (2009). Inactivation of PadR, the repressor of the phenolic acid stress response, by molecular interaction with Usp1, a universal stress protein from Lactobacillus plantarum, in Escherichia coli. Appl. Environ. Microbiol. 75, 52735283. doi: 10.1128/aem.00774-09

Handwerger, S., Pucci, M. J., Volk, K. J., Liu, J., and Lee, M. S. (1994). Vancomycin-resistant Leuconostoc mesenteroides and Lactobacillus casei synthesize cytoplasmic peptidoglycan precursors that terminate in lactate. J. Bacteriol. 176, 260-264. doi: 10.1128/jb.176.1.260-264.1994

Hellemans, J., Mortier, G., De Paepe, A., Speleman, F., and Vandesompele, J. (2007). qBase relative quantification framework and software for management and automated analysis of real-time quantitative PCR data. Genome Biol. 8:R19.

Hugo, A. A., Tymczyszyn, E. E., Gomez-Zavaglia, A., and Perez, P. F. (2012). Effect of human defensins on lactobacilli and liposomes. J. Appl. Microbiol. 113, 1491-1497. doi: 10.1111/j.1365-2672.2012.05433.x

Hutchings, M. I., Hong, H. J., and Buttner, M. J. (2006). The vancomycin resistance VanRS two-component signal transduction system of Streptomyces coelicolor. Mol. Microbiol. 59, 923-935. doi: 10.1111/j.1365-2958.2005.04953.x

Ito, M., Kim, Y. G., Tsuji, H., Takahashi, T., Kiwaki, M., Nomoto, K., et al. (2014). Transposon mutagenesis of probiotic Lactobacillus casei identifies asn $\mathrm{H}$, an asparagine synthetase gene involved in its immune-activating capacity. PLoS One 9:e83876. doi: 10.1371/journal.pone.0083876

Johnson, B. R., Hymes, J., Sanozky-Dawes, R., Henriksen, E. D., Barrangou, R., and Klaenhammer, T. R. (2016). Conserved S-Layer-associated proteins revealed by exoproteomic survey of S-Layer-forming lactobacilli. Appl. Environ. Microbiol. 82, 134-145. doi: 10.1128/aem.01968-15

Klare, I., Konstabel, C., Werner, G., Huys, G., Vankerckhoven, V., Kahlmeter, G., et al. (2007). Antimicrobial susceptibilities of Lactobacillus, Pediococcus and Lactococcus human isolates and cultures intended for probiotic or nutritional use. J. Antimicrob. Chemother. 59, 900-912. doi: 10.1093/jac/dkm035
Koh, A., De Vadder, F., Kovatcheva-Datchary, P., and Bäckhed, F. (2016). From dietary fiber to host physiology: short-chain fatty acids as key bacterial metabolites. Cell 165, 1332-1345. doi: 10.1016/j.cell.2016.05.041

Koponen, J., Laakso, K., Koskenniemi, K., Kankainen, M., Savijoki, K., Nyman, T. A., et al. (2012). Effect of acid stress on protein expression and phosphorylation in Lactobacillus rhamnosus GG. J. Proteomics 75, 1357-1374. doi: 10.1016/j.jprot.2011.11.009

Layec, S., Decaris, B., and Leblond-Bourget, N. (2008). Diversity of Firmicutes peptidoglycan hydrolases and specificities of those involved in daughter cell separation. Res. Microbiol. 159, 507-515. doi: 10.1016/j.resmic.2008.06.008

Lebeer, S., Claes, I. J., Balog, C. I., Schoofs, G., Verhoeven, T. L., Nys, K., et al. (2012). The major secreted protein Msp1/p75 is O-glycosylated in Lactobacillus rhamnosus GG. Microb. Cell Fact 11:15. doi: 10.1186/1475-2859-11-15

Letunic, I., Doerks, T., and Bork, P. (2014). SMART: recent updates, new developments and status in 2015. Nucleic Acids Res. 43, D257-D260. doi: 10. 1093/nar/gku949

Licandro-Seraut, H., Brinster, S., van de Guchte, M., Scornec, H., Maguin, E., Sansonetti, P., et al. (2012). Development of an efficient in vivo system (PjuncTpaseIS1223) for random transposon mutagenesis of Lactobacillus casei. Appl. Environ. Microbiol, 78, 5417-5423.

Licandro-Seraut, H., Gury, J., Tran, N. P., Barthelmebs, L., and Cavin, J. F. (2008). Kinetics and intensity of the expression of genes involved in the stress response tightly induced by phenolic acids in Lactobacillus plantarum. J. Mol. Microbiol. Biotechnol. 14, 41-47. doi: 10.1159/000106081

Licandro-Seraut, H., Scornec, H., Pedron, T., Cavin, J. F., and Sansonetti, P. J. (2014). Functional genomics of Lactobacillus casei establishment in the gut. Proc. Natl. Acad. Sci. U.S.A. 111, E3101-E3109.

Lozupone, C. A., Stombaugh, J. I., Gordon, J. I., Jansson, J. K., and Knight, R. (2012). Diversity, stability and resilience of the human gut microbiota. Nature 489, 220-230. doi: 10.1038/nature11550

Mackey, T., Lejeune, V., Janssens, M., and Wauters, G. (1993). Identification of vancomycin-resistant lactic bacteria isolated from humans. J. Clin. Microbiol. 31, 2499-2501. doi: 10.1128/jcm.31.9.2499-2501.1993

Makarova, K., Slesarev, A., Wolf, Y., Sorokin, A., Mirkin, B., Koonin, E., et al. (2006). Comparative genomics of the lactic acid bacteria. Proc. Natl. Acad .Sci. U.S.A. 103, 15611-15616.

Matos, R. C., Schwarzer, M., Gervais, H., Courtin, P., Joncour, P., Gillet, B., et al. (2017). D-Alanylation of teichoic acids contributes to Lactobacillus plantarummediated Drosophila growth during chronic undernutrition. Nat. Microbiol. 2, 1635-1647. doi: 10.1038/s41564-017-0038-x

Meyrand, M., Boughammoura, A., Courtin, P., Mezange, C., Guillot, A., and Chapot-Chartier, M. P. (2007). Peptidoglycan N-acetylglucosamine deacetylation decreases autolysis in Lactococcus lactis. Microbiology 153, 32753285. doi: 10.1099/mic.0.2007/005835-0

Milani, C., Duranti, S., Bottacini, F., Casey, E., Turroni, F., Mahony, J., et al. (2017). The first microbial colonizers of the human gut: composition, activities, and health implications of the infant gut microbiota. Microbiol. Mol. Biol. Rev. 81:e00036-17. doi: 10.1128/MMBR.00036-17

Molle, V., and Buttner, M. J. (2000). Different alleles of the response regulator gene bldM arrest Streptomyces coelicolor development at distinct stages. Mol. Microbiol. 36, 1265-1278. doi: 10.1046/j.1365-2958.2000.01977.x

Munoz-Provencio, D., Llopis, M., Antolin, M., de Torres, I., Guarner, F., PerezMartinez, G., et al. (2009). Adhesion properties of Lactobacillus casei strains to resected intestinal fragments and components of the extracellular matrix. Arch. Microbiol. 191, 153-161. doi: 10.1007/s00203-008-0436-9

Neuhaus, F. C., and Baddiley, J. (2003). A continuum of anionic charge: structures and functions of D-alanyl-teichoic acids in gram-positive bacteria. Microbiol. Mol. Biol. Rev. 67, 686-723. doi: 10.1128/mmbr.67.4.686-723.2003

Palud, A., Scornec, H., Cavin, J. F., and Licandro, H. (2018). New genes involved in mild stress response identified by transposon mutagenesis. Front. Microbiol. 9:535. doi: 10.3389/fmicb.2018.00535

Palumbo, E., Deghorain, M., Cocconcelli, P. S., Kleerebezem, M., Geyer, A., Hartung, T., et al. (2006). D-alanyl ester depletion of teichoic acids in Lactobacillus plantarum results in a major modification of lipoteichoic acid composition and cell wall perforations at the septum mediated by the Acm2 autolysin. J. Bacteriol 188, 3709-3715. doi: 10.1128/jb.188.10.3709-3715.2006

Perea Velez, M., Verhoeven, T. L., Draing, C., Von Aulock, S., Pfitzenmaier, M., Geyer, A., et al. (2007). Functional analysis of D-alanylation of lipoteichoic acid 
in the probiotic strain Lactobacillus rhamnosus GG. Appl. Environ. Microbiol. 73, 3595-3604. doi: 10.1128/aem.02083-06

Perpetuini, G., Pham-Hoang, B. N., Scornec, H., Tofalo, R., Schirone, M., Suzzi, G., et al. (2016). In Lactobacillus pentosus, the olive brine adaptation genes are required for biofilm formation. Int. J. Food Microbiol. 216, 104-109. doi: 10.1016/j.ijfoodmicro.2015.10.002

Raychaudhuri, D., and Chatterjee, A. N. (1985). Use of resistant mutants to study the interaction of triton X-100 with Staphylococcus aureus. J. Bacteriol. 164, 1337-1349. doi: 10.1128/jb.164.3.1337-1349.1985

Regulski, K., Courtin, P., Meyrand, M., Claes, I. J., Lebeer, S., Vanderleyden, J., et al. (2012). Analysis of the peptidoglycan hydrolase complement of Lactobacillus casei and characterization of the major gamma-D-glutamyl-Llysyl-endopeptidase. PLoS One 7:e32301. . doi: 10.1371/journal.pone.0032301

Rico, J., Yebra, M. J., Pérez-Martínez, G., Deutscher, J., and Monedero, V. (2008). Analysis of ldh genes in Lactobacillus casei BL23: role on lactic acid production. J. Ind. Microbiol. Biotechnol. 35, 579-586. doi: 10.1007/s10295-008-0319-8

Rolain, T., Bernard, E., Beaussart, A., Degand, H., Courtin, P., Egge-Jacobsen, W., et al. (2013). O-glycosylation as a novel control mechanism of peptidoglycan hydrolase activity. J. Biol. Chem. 288, 22233-22247. doi: 10.1074/jbc.m113. 470716

Rossetti, L., Carminati, D., Zago, M., and Giraffa, G. (2009). A qualified presumption of safety approach for the safety assessment of grana padano whey starters. Int. J. Food Microbiol. 130, 70-73. doi: 10.1016/j.ijfoodmicro.2009. 01.003

Sambrook, J., Fritsch, E. F., and Maniatis, T. (1989). Molecular Cloning: a Laboratory Manual, 2nd Edn. Cold Sring Harbor, NY: Cold Spring Harbor Laboratory Press.

Scornec, H., Tichit, M., Bouchier, C., Pedron, T., Cavin, J. F., Sansonetti, P. J., et al. (2014). Rapid 96-well plates DNA extraction and sequencing procedures to identify genome-wide transposon insertion sites in a difficult to lyse bacterium: Lactobacillus casei. J. Microbiol. Methods 106, 78-82. doi: 10.1016/j.mimet.2014. 08.001

Sengupta, R., Altermann, E., Anderson, R. C., McNabb, W. C., Moughan, P. J., and Roy, N. C. (2013). The role of cell surface architecture of lactobacilli in host-microbe interactions in the gastrointestinal tract. Mediators Inflamm. 2013:237921.

Seth, A., Yan, F., Polk, D. B., and Rao, R. K. (2008). Probiotics ameliorate the hydrogen peroxide-induced epithelial barrier disruption by a PKC- and MAP kinase-dependent mechanism. Am. J. Physiol. Gastrointest Liver Physiol. 294, G1060-G1069.

Smit, E., Oling, F., Demel, R., Martinez, B., and Pouwels, P. H. (2001). The S-layer protein of Lactobacillus acidophilus ATCC 4356: identification and characterisation of domains responsible for S-protein assembly and cell wall binding. J. Mol. Biol. 305, 245-257. doi: 10.1006/jmbi.2000.4258

Sommer, F., Anderson, J. M., Bharti, R., Raes, J., and Rosenstiel, P. (2017). The resilience of the intestinal microbiota influences health and disease. Nat. Rev. Microbiol. 15, 630-638. doi: 10.1038/nrmicro.2017.58

Sonnenburg, J. L., and Bäckhed, F. (2016). Diet-microbiota interactions as moderators of human metabolism. Nature 535, 56-64. doi: 10.1038/ nature 18846

Steen, A., Palumbo, E., Deghorain, M., Cocconcelli, P. S., Delcour, J., Kuipers, O. P., et al. (2005). Autolysis of Lactococcus lactis is increased upon D-alanine depletion of peptidoglycan and lipoteichoic acids. J. Bacteriol. 187, 114-124. doi: 10.1128/jb.187.1.114-124.2005

Stefanovic, E., Kilcawley, K. N., Roces, C., Rea, M. C., O’Sullivan, M., Sheehan, J. J., et al. (2018). Evaluation of the potential of Lactobacillus paracase $i$ adjuncts for flavor compounds development and diversification in short-aged cheddar cheese. Front. Microbiol. 9:1506. doi: 10.3389/fmicb.2018.01506

Stock, A. M., Robinson, V. L., and Goudreau, P. N. (2000). Two-component signal transduction. Annu. Rev. Biochem. 69, 183-215.

Takeuchi, O., and Akira, S. (2010). Pattern recognition receptors and inflammation. Cell 140, 805-820. doi: 10.1016/j.cell.2010.01.022

The Human Microbiome Project Consortium. (2012). Structure, function and diversity of the healthy human microbiome. Nature 486, 207-214. doi: 10.1038/ nature11234

Thiéry, J.-P. (1967). Mise en évidence des polysaccharides sur coupes fines en microscopie électronique. J. Microscopie 6, 987-1018.

van de Guchte, M., Serror, P., Chervaux, C., Smokvina, T., Ehrlich, S. D., and Maguin, E. (2002). Stress responses in lactic acid bacteria. Antonie Van Leeuwenhoek 82, 187-216.

Wilks, M., Wiggins, R., Whiley, A., Hennessy, E., Warwick, S., Porter, H., et al. (2004). Identification and $\mathrm{H} 2 \mathrm{O} 2$ production of vaginal lactobacilli from pregnant women at high risk of preterm birth and relation with outcome. J. Clin. Microbiol. 42, 713-717. doi: 10.1128/jcm.42.2.713-717.2004

Yan, F., Cao, H., Cover, T. L., Whitehead, R., Washington, M. K., and Polk, D. B. (2007). Soluble proteins produced by probiotic bacteria regulate intestinal epithelial cell survival and growth. Gastroenterology 132, 562-575. doi: 10.1053/ j.gastro.2006.11.022

Yan, F., Liu, L., Dempsey, P. J., Tsai, Y. H., Raines, E. W., Wilson, C. L., et al. (2013). A Lactobacillus rhamnosus GG-derived soluble protein, p40, stimulates ligand release from intestinal epithelial cells to transactivate epidermal growth factor receptor. J. Biol. Chem. 288, 30742-30751. doi: 10.1074/jbc.m113.492397

Yeaman, M. R., and Yount, N. Y. (2003). Mechanisms of antimicrobial peptide action and resistance. Pharmacol. Rev. 55, 27-55. doi: 10.1124/pr.55.1.2

Zhang, Y. C., Zhang, L. W., Tuo, Y. F., Guo, C. F., Yi, H. X., Li, J. Y., et al. (2010). Inhibition of Shigella sonnei adherence to HT-29 cells by lactobacilli from Chinese fermented food and preliminary characterization of S-layer protein involvement. Res. Microbiol. 161, 667-672. doi: 10.1016/j.resmic.2010. 06.005

Zitvogel, L., Daillère, R., Roberti, M. P., Routy, B., and Kroemer, G. (2017). Anticancer effects of the microbiome and its products. Nat. Rev. Microbiol. 15, 465-478. doi: 10.1038/nrmicro.2017.44

Conflict of Interest: The authors declare that the research was conducted in the absence of any commercial or financial relationships that could be construed as a potential conflict of interest.

Copyright (C) 2020 Scornec, Palud, Pédron, Wheeler, Petitgonnet, Boneca, Cavin, Sansonetti and Licandro. This is an open-access article distributed under the terms of the Creative Commons Attribution License (CC BY). The use, distribution or reproduction in other forums is permitted, provided the original author(s) and the copyright owner(s) are credited and that the original publication in this journal is cited, in accordance with accepted academic practice. No use, distribution or reproduction is permitted which does not comply with these terms. 